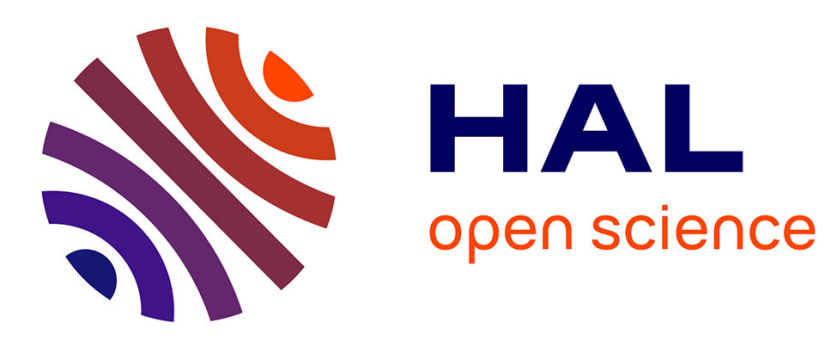

\title{
The central nervous system of ascidian larvae Clare Hudson
}

\section{To cite this version:}

Clare Hudson. The central nervous system of ascidian larvae. Wiley Interdisciplinary Reviews: Developmental Biology, 2016, 5 (5), pp.538-561 10.1002/wdev.239 . hal-01336969

\section{HAL Id: hal-01336969 \\ https: / hal.sorbonne-universite.fr/hal-01336969}

Submitted on 24 Jun 2016

HAL is a multi-disciplinary open access archive for the deposit and dissemination of scientific research documents, whether they are published or not. The documents may come from teaching and research institutions in France or abroad, or from public or private research centers.
L'archive ouverte pluridisciplinaire HAL, est destinée au dépôt et à la diffusion de documents scientifiques de niveau recherche, publiés ou non, émanant des établissements d'enseignement et de recherche français ou étrangers, des laboratoires publics ou privés. 


\section{Clare Hudson}

clare.hudson@obs-vlfr.fr

Sorbonne Universités, UPMC Univ Paris 06, CNRS, Laboratoire de Biologie du Développement de Villefranche-sur-mer, Observatoire Océanologique, 06230, Villefranchesur-mer, France

The central nervous system of ascidian larvae

Published in WIREs Dev Biol, juin 2016. doi: 10.1002/wdev.239 


\section{Abstract}

Ascidians are marine invertebrate chordates. Their tadpole larvae contain a dorsal tubular nervous system, resulting from the rolling up of a neural plate. Along the anterior-posterior axis, the central nervous system (CNS) is organised into a sensory vesicle, neck, trunk ganglion and tail nerve cord and consists of approximately only 330 cells, of which around 100 are thought to be neurons. The organisation of distinct neuronal cell types and neurotransmitter gene expression within the CNS has been described. The unique developmental mode of ascidians, with a small number of cells and a fixed cell division pattern, allows individual cells to be traced throughout development. This feature has led to the complete documentation of the cell lineages of certain cell types in the CNS. Thus a step-bystep understanding of nervous system development from the initial stages of neural induction to the neurogenesis of individual neurons is a feasible goal. The genetic control of neural fate induction and early neural plate patterning are now well understood. The molecular mechanisms specifying the cholinergic neurons of the trunk ganglion as well as the pigment cells of the sensory organs are also well elucidated. In addition, studies have begun on the morphogenetic processes of neurulation. Remaining challenges include building an embryonic atlas integrating gene expression patterns, cell lineage and neuronal cell types as well as developing the gene regulatory networks of cell fate specification and integrating them with the genetic control of morphogenesis.

\section{Introduction}

Ascidians are urochordates, or tunicates, which together with cephalochordates and vertebrates, belong to the phylum, or superphylum, Chordata [1]. Within the chordata, ascidians are phylogenetically more closely related to vertebrates, with cephalochordates the earliest branching chordates [2]. Chordates are characterised by the presence of a notochord, dorsal hollow neural tube (the formation of which is the topic of this review), and pharyngeal slits [1]. While both solitary and colonial life styles exist in ascidians, developmental biology studies have mainly focused on two solitary ascidian species, Halocynthia roretzi and Ciona intestinalis. It should be noted that Ciona intestinalis is in fact two cryptic species termed either $C$. intestinalis subtype $A$ and $B$ or $C$. robusta and $C$. intestinalis [35]. Ciona sp. are found throughout the world and a vast array of molecular tools have been developed in the last decades [6-8]. In this review I will mainly focus on Ciona.

Ascidians develop with a small number of cells, a stereotypic cell division pattern and early fate restriction. For example, gastrulation begins at the 112-cell stage of development, a stage when most embryonic cells are already fate restricted to one tissue type, and a fully formed larva contains approximately 2500 cells. The small size and relative transparency of ascidian embryos also aid microscopic and cellular analysis of development. These features allow individual cells to be named and followed during development. The cell lineage of the central nervous system (CNS) is well 
described until tailbud stages and the lineage of some larval neurons is completely documented [915]. Despite a mode of development very different from classical vertebrate models, the fate maps of ascidian and vertebrate pre-gastrula stage embryos are nonetheless comparable (Figure 1) [16]. The ascidian central nervous system, like that in vertebrates, largely arises on the notochord side of the blastula stage embryo (Figure 1). The neural tube is made by the rolling up of the neural plate, a process called primary neurulation, as is observed in most vertebrates $[12,17,18]$. At tailbud stages, the developing CNS of ascidians can be directly compared to its counterpart in vertebrates, with many conserved molecular features such as expression of the Otx gene anteriorly and Hox genes posteriorly $[10,19,20]$. Despite a similar fate-map and larval body plan between ascidians and vertebrates, the molecular mechanisms leading to tadpole formation are not necessarily well conserved [16,21-23]. Thus, studying ascidians can both highlight which chordate developmental strategies are under strong evolutionary constraints as well as those that are subject to a high level of mechanistic plasticity. The purpose of this review is to describe the formation of the ascidian CNS in its own right. The simplicity and fixed cell lineage of ascidian larval development means that it should be possible to understand, with step-by-step precision, the specification of every cell of the larval CNS. This review will describe to what extent this has been achieved and the challenges that remain. Gene naming follows published guidelines, with alternative names shown in brackets the first time a modified gene name is mentioned [24]. Cell lineage naming follows the nomenclature rule developed by Edwin G. Conklin [25].

\section{AN OVERVIEW OF THE ASCIDIAN LARVAL CENTAL NERVOUS SYSTEM}

The CNS of ascidian larvae is separated into three morphological domains, the anterior-most sensory vesicle, followed by a narrow 'neck' region, a trunk ganglion (also called visceral ganglion) and tail nerve cord (Figure 2a). Homologies between the vertebrate and the ascidian CNS are not entirely resolved $[10,19,20,26-28]$. An excellent discussion on regional homologies in the CNS as well as the evidence for a dipartite versus tripartite organisation of the ascidian CNS can be found in Ikuta and Saiga, 2007 [10]. The following description is a tentative synthesis of the published literature (Figure 2a). Along the anterior-posterior axis, expression of Otx suggests that the sensory vesicle corresponds to the forebrain of vertebrates. Gene expression patterns suggest that a large part of the ventral and lateral sensory vesicle represents a proto-hypothalamic-retinal territory [29-32]. More posteriorly, a Pax2/5/8a+/Otx-/Hoxl- domain in the neck region corresponds to the vertebrate mid-hindbrain boundary with a Pax2/5/8a+/Hox $1+/$ Phox $2+$ domain, also in the neck, corresponding to the hindbrain. Finally the Hox + trunk ganglion and probably also the tail nerve cord correspond to the spinal cord of vertebrates. Whether the tail nerve cord corresponds to any part of the vertebrate neural tube has been controversial $[19,28]$. During these earlier studies it was thought that the tail nerve cord was devoid of neurons. We know now that this is not the case and some neurons are indeed present in the tail nerve 
cord. In particular, the anterior caudal inhibitory neurons (ACINs) that constitute part of the probable central pattern generator are derived from the Hox+ anterior nerve cord [10,33-35]. For this reason, I include the anterior tail nerve cord as comparable to the vertebrate spinal cord (Figure 2a).

Conservation of dorsal-ventral gene expression patterns have also been described between ascidian and vertebrates [28,36-38]. Interestingly, at the level of the trunk ganglion, differential gene expression in the five pairs of cholinergic neurons that are aligned along the anterior-posterior axis is similar to that observed along the dorsal-ventral axis of the vertebrate spinal cord, suggesting some convergence between the two axes in ascidians [39]. However, a note of caution concerning this section: similar gene expression patterns do not necessarily imply equivalent roles for homologous genes between ascidians and vertebrates [21,22], an issue that can only be resolved by functional comparisons. While the focus of this review is the larval CNS, it is worth noting the fate of the CNS after metamorphosis. Following metamorphosis, the adult CNS is constructed predominantly from the non-neuronal ependymal cells of the larval CNS, suggesting that the ependymal cells have stem celllike properties $[40,41]$. The anterior-posterior axis of the larval and adult nervous systems is largely maintained following metamorphosis, although the entire tail nerve cord is lost.

\section{LARVAL BEHAVIOUR}

A CNS is required, ultimately, to govern the behaviour of the organism. Ascidian larvae exhibit two types of movements, asymmetrical tail flicks and symmetrical swimming [42]. Tail flicks are used during and just after hatching, which may assist in hatching from the chorion [42]. Tail flicks may also be used as a 'warm up' prior to symmetrical swimming [42]. Symmetrical swimming is powered by undulating tail motion with left and right muscle bands contacting alternatively in a regular frequency $[34,42,43]$. This type of spontaneous regular swimming is thought to be generated by a central pattern generator in the nervous system $[33,44]$. Muscular contraction is thought to be coordinated by the coupling of muscle cells by gap junctions $[42,45]$. After hatching, larvae exhibit two characteristic behaviours: firstly, they swim upwards with negative geotaxis, followed later by downward, negative phototactic, swimming [43,46-51]. During this later phase, which takes place 3-4 hours after hatching, larvae exhibit a 'shadow response', such that swimming frequency increases in response to a reduction in light $[43,47,50-52]$. The first phase may act to disperse the larvae whereas the second phase helps the larvae find a shaded place prior to metamorphosis $[46,49]$.

Neuromuscular transmission is cholinergic and takes place via the muscle nicotinic acetylcholine receptor (nAChR) channel $[52,53]$. The ability to grade the strength of muscle contraction (thus tail flexion), important for changing the force (tail beat frequency) and direction of swimming, depends upon specific residues in the nAChR channel pore [52]. A nerve-cord trunk 
ganglion preparation (such that the sensory vesicle is removed) is able to generate co-ordinated (L-R alternating) swimming in response to glutamate [34]. This suggests that the nerve-cord and trunk ganglion contain the central pattern generator, which can be activated by glutamatergic stimulation from the sensory vesicle. Intact glycinergic signalling is required for the L-R co-ordination of swimming [34], whereas GABA treatment inhibits swimming, reducing movement to single tail flicks [54]. The expression pattern of genes involving in production or processing of these neurotransmitters will be described in the following section.

\section{CELL TYPES IN THE CENTRAL NERVOUS SYSTEM}

The entire CNS consists of around 330 cells, with an estimated 100 neurons [55]. In this section each part of the larval CNS and its composite cell types will be described (Figure 3).

\section{Sensory vesicle}

The sensory vesicle is the ascidian larval brain and is the most intricate part of the CNS containing around two thirds of its constituent cells [55]. One of the most prominent features of the sensory vesicle are the pigmented cells (Figure 3a) [56]. The pigmented cells contribute to the sense organs, the otolith (also called statocyte) and the ocellus. The otolith is thought to be a gravity receptor and required for the upward swimming behaviour of hatchlings $[46,51,57]$. The otolith is a unicellular organ, consisting of a foot part, anchored in the ventral wall of the sensory vesicle, and a free part containing a large, almost round, melanin granule within the cavity of the sensory vesicle $[51,58,59]$. The otolith itself is glutamatergic [60]. Neurons in the ventral wall of the sensory vesicle project sensory endings that contact the otolith cell body [57,61]. It is proposed that these projections detect movement of the otolith. The axons of these neurons project to the trunk ganglion. These neurons may correspond to three antennal neurons identified by Imai and Meinertzhagen [62] and glutamatergic neurons identified by Horie et al [60].

The ocellus is a multicellular structure, situated on the right hand side of the sensory vesicle (Figure 3a). Ocellus function is required for the larval photoresponse $[46,51,63-65]$. It consists of a cup-shaped pigment cell, easily distinguished from the otolith by its small and dispersed pigment granules, photoreceptors and 3 lens cells. The photoreceptors are ciliary and cover the right-lateral surface of the pigment cup [59,66,67]. One group of photoreceptors (group I), of which there are 18 to 23 , extend processes through the pigment cup so that their outer segments lie, aligned in five rows, within the pigment cup $[59,64,66,67]$. A second group (II), also on the surface of the pigment cup, have outer segments within the lumen of the sensory vesicle and number 8 to 11 [64]. Some, but not 
all, of the photoreceptors associated with the ocellus are glutamatergic, while some appear to be GABA/glycinergic $[33,60,68,69]$. Photo-transduction and visual cycle genes of the ocellus photoreceptors have been reviewed elsewhere [56,70]. The opening of the pigmented cup is ventralanterior [59]. At the entrance to the cup and slightly within the opening of the cup itself are three lens cells $[59,66]$. These lens cells are not considered to be homologous to vertebrate lens cells [71].

A third group of photoreceptors (type III) are present in the left ventral wall of the sensory vesicle close to the otolith (Figure 3a). They have a spherical shaped and their outer segments are exposed to the lumen of the sensory vesicle $[64,72]$. There are estimated to be 6-7 type III photoreceptors. It is not yet clear what the role of these photoreceptors is. Just posterior to the type III photoreceptors are the coronet cells, situated on the left ventral posterior wall of the sensory vesicle. These cells extend bulbous modified cilia into the sensory vesicle $[59,72]$. The coronet cells are thought to represent some kind of pressure organ, although the function remains to be clarified $[32,51,59]$. There are estimated to be 19 coronet cells, at least some of which are dopaminergic [31]. Closely associated with the coronet cells are other dopaminergic cells including at least one neuron and, together, these cells constitute the only dopaminergic cells in the larvae $[31,32]$. Inhibition of the serotonin transporter (SERT, which presumably acts during the uptake of dopamine in ascidians) modulates both spontaneous and shadow response swimming [32]. To the left and adjacent to the coronet cells, a group of ependymal cells extend their cilia between the bulbs of the coronet cells [72].

Some neurons of the sensory vesicle have been described using a pan-neuronal promoter (synaptotagmin) to drive the GFP reporter [62]. This method identified the eminens cell and the L1 neuron (Figure 3a). The eminens neuron, of which there is thought to be only one per larva, has large soma in the dorsal posterior sensory vesicle. This neuron may receive the axon terminals of the papilla neurons, and its axon projects straight to proximal tail [62]. The L1 neuron is a large interneuron in the posterior ventral wall of the sensory vesicle, it projects dorsally, then posteriorly to proximal tail and there are at least two per larva [62]. Both of these neurons are thought to be GABAergic [68].

The posterior part of the sensory vesicle is seen as the processing hub of brain activity, integrating sensory input from sensory organs and controlling motor output [44]. Regionalised expression of glutamatergic, GABA/glycergic (most of which are likely to be GABAergic) and cholinergic markers in this part of the CNS suggests the presence of a high number of neurons, whose identity and cell lineage are largely unknown $[33,54,60,68]$.

\section{Neck}


The narrow neck region between the sensory vesicle and trunk ganglion is devoid of neurons. Interestingly, the Pax2/5/8a+/Hox $1+/$ Phox $2+$ domain of the neck will generate brachial basket cholinergic motoneurons after metamorphosis $[19,41]$.

\section{Trunk Ganglion}

The trunk ganglion corresponds to a swelling of the neural tube, situated between the neck and the tail nerve cord (Figures 2a, 3a). In the literature, it has been variously called the visceral and the trunk ganglion. Since this region does not produce the visceral neurons, we refer to it as the trunk ganglion as proposed by Dufour et al [19]. The trunk ganglion contains 5 pairs of ventro-lateral cholinergic neurons, at least 2 pairs of which are motoneurons [73]. This group of cholinergic neurons is sometimes referred to as the motor ganglion in the literature. The cholinergic motoneuron axons innervate the anterior muscle bands with innervation of the dorsal muscle band clearly demonstrated, although whether the medial and ventral muscles are also innervated is not agreed upon $[33,42,52,62,73]$. Subunits of the nAChR are broadly expressed in tail muscle [52]. Using fusion proteins to visualise their localisation, $\mathrm{nAChR}$ subunits have been shown to co-localise precisely with the motor axon terminals at the anterior-most dorsal muscle as well as with the descending motor axons in more posterior dorsal muscle cells [52]. The cell lineage of the five pairs of cholinergic neurons is known, each cell is characterised by different gene expression and each possesses distinct neuronal characteristics (Figure 3a) [39,73]. The anterior-most of these cholinergic neurons, A12.239, expresses $D m b x$, projects a contralateral thin axon, and is thought to be an interneuron. Next, another probable interneuron, A13.474, expresses Vsx and projects a thin axon towards the tail. A11.118 is clearly a motoneuron, it expresses $N k 6$ and $M n x$, and projects axons with endplates that contact the lateral surfaces of anterior tail muscle cells. A11.117 is a Vsx+, Pitx + probable interneuron characterised by a thin axon and the presence of neurites on the soma. Finally, A10.57 is an Islet+, $M n x+$ probable motoneuron, descending an axon with small putative endplates close to the muscle. The molecular mechanisms leading to specification of these cholinergic neurons is known in precise detail and will be discussed later.

Other neurons present in the trunk ganglion were identified using the pan-neuronal synaptotagmin promoter [62]. A potential motoneuron was described to extend a ventrally projecting axon with direct apposition to ventral muscle cells. This is presumably distinct from the cholinergic motoneurons described above, which are not thought to project to the ventral muscles $[33,73]$. The trunk ganglion also contains the ovoid neuron, which extends a long axon terminating mid-way down the tail with no endplates and may be cholinergic $[62,68]$. In the dorsal part of the trunk ganglion are at least three contrapelo neurons with ascending axons [62]. The presence of GABA/Glycinergic (most 
likely GABAergic), other cholinergic and potentially serotonergic neurons are also reported in the trunk ganglion $[33,54,68,69,74]$.

\section{Tail nerve cord}

The tail nerve cord is a tube consisting of only four cells in cross section, one dorsal, one ventral and two lateral. Underneath the tail nerve cord, at its ventro-lateral corners run bundles of caudally projecting axon tracts $[18,62,75]$. The tail nerve cord appears to be made up of predominantly ciliated ependymal cells $[72,75]$. However, recently, neurons have been identified in the tail nerve cord. In the anterior part of the tail nerve cord are two pairs of GABA/glycinergic (most likely glycinergic) anterior caudal inhibitory neurons (ACINs) [33]. ACIN axons extend anteriorly and contralaterally, appearing to terminate on the contralateral cholinergic axon bundles [33]. Consistent with a possible role for glycinergic inputs into motor activity, the cholinergic neurons themselves (as well as muscle cells) express a glycine receptor and glycinergic function is required for the left-right co-ordination of swimming [34]. The ACINs may themselves be regulated by the ipsilateral cholinergic neurons whose axons contact the ACIN cell bodies. The cholinergic motoneurons and ACINs are proposed to form a circuit with ipsilateral activation and contralateral inhibition generating reciprocal muscle contractions, thus forming the central pattern generator [33].

At least two types of planate neurons were also observed along the ventro-lateral axon tracts, with either anterior or posterior projecting neurites [62]. These neurons, most likely correspond to cholinergic neurons identified in Horie et al (2010), based on their similar morphology and position. There are an estimated 12 to 15 planate neurons [33]. Another possible tail neuron is the caudal neuron in the anterior tail nerve cord that has a unique broad multipolar terminal with at least three branches (and no endplates) [62]. However, this neuron was only observed in one preparation and therefore its identity needs to be confirmed by further studies.

\section{NEURONS OF THE PERIPHERAL NERVOUS SYSTEM}

The central nervous system would not function correctly without the sensory input from the peripheral nervous system (PNS). The peripheral nervous system consists of the papillary neurons of the adhesive papillae, the epidermal sensory neurons and the bipolar tail neurons (Figure 3b) $[60,76,77]$. The palps, an adhesive organ that are required for attachment to a substrate prior to metamorphosis, are situated at the anterior end of the embryo. There are two spindle shaped neurons in each palp, which are most likely chemosensory in nature $[76,78,79]$. Epidermal sensory neurons are classified as rostral and apical trunk epidermal neurons (RTEN, ATEN) and caudal epidermal neurons (CEN), 
which are found both dorsally (d) and ventrally (v) in the tail. The epidermal sensory neurons are proposed to be mechanosensory neurons, though their function is not entirely clear $[60,68,76,79]$. Most PNS sensory neurons appear to be glutamatergic and innervate the CNS at the level of the sensory vesicle and trunk ganglion [60,76]. The papillary and epidermal sensory neurons possess cilia, which extend into the tunic $[72,80]$. The epidermal neurons also extend processes forming an unusual interconnecting dendritic network throughout the larval tunic [79,81]. The bipolar tail neurons (BTNs) are generated from posterior epidermis and migrate anteriorly and dorsally to their final position outside, dorsal to and closely associated with the CNS $[76,82]$. CENs in the overlying dorsal ectoderm form synaptic contacts with the BTNs, which extend processes forming multiple synaptic contacts with two pairs of motoneurons (A11.118 and A.10.57) [82]. The BTNs are most likely GABAergic [69].

\section{EMBRYONIC ORIGIN OF THE NERVOUS SYSTEM}

At the 8-cell stage of development, cell division separates the animal and vegetal hemispheres of the embryo and the four founder lineages are born $[14,25,83]$. These are named, A- and B-for vegetal lineages (generates mostly mesendoderm and some neural) and a- and b- for animal lineages (mainly epidermis and neural) (Figure 2b). The nervous system derives from the a-, b- and A-lineages (Figure 2) $[12-14,25,83]$. The A-lineages become neural fate restricted at the 64 -cell stage of development (equivalent to the blastula stage), whereas the a- and b-lineages do so at the 112-cell stage (early gastrula) (Figure $2 b-f$ ). The mechanisms of neural fate segregation in these different lineages will be addressed later.

At the 6-row neural plate stage, the cells of the neural plate are arranged in a striking grid-like array (Figure 2g) $[12,13]$. The six rows of cells along the anterior-posterior axis are named as rows I to VI, with row I the most posterior. Perpendicularly, the eight columns of cells are named columns 1 to 4 with the pair of medial columns named column 1 and the lateral most columns, column 4 . Rows I and II derive from the A-lineages and will generate the lateral and ventral cells of the posterior sensory vesicle, trunk ganglion and tail nerve cord (Figure 2)[9]. Rows III-VI are a-line derived, with rows III and IV giving rise to the anterior-most part of the sensory vesicle as well as part of the oral siphon primordium $[9,14,84,85]$. Due to their position in the neural plate and close association with the CNS lineages, rows V and VI are considered as part of the neural plate. However, they do not contribute to the CNS, but instead give rise to a specialised region of the anterior ectoderm. This region includes the palps as well as a proto-placodal-like neurogenic ectoderm from which the anterior trunk epidermal neurons (aATENs) are generated (Figures 3b, 4a) $[14,86,87]$. In this review rows V and VI of the neural plate will be referred to as non-CNS anterior neural plate. Lateral to the A- and a-derived neural 
plate grid of cells are the b-line neural cells. b-line cells form the dorsal most row of cells of the neural tube, from the posterior part of the sensory vesicle to the tail nerve cord (Figure 2)[9,14]. Two muscle precursors, intimately associated with the neural plate, are specified at the lateral-posterior border of the A-line derived neural plate and are specified during posterior neural plate patterning (Figure $2 \mathrm{~g}$ ) [88]. For some cell types in the larval CNS, the cell lineage is completely documented and will be discussed later in this review.

\section{PNS and the neural border cells}

Most PNS neurons arise from cells surrounding the neural plate (Figure 4a). The non-CNS anterior neural plate will generate the palps and ATENs $[9,14,86,89]$. In Halocynthia it has been shown that the RTEN are induced by signals from the non-CNS anterior neural plate in the epidermis just anterior to it [89]. Lateral to the neural plate are non-CNS b6.5 derivatives (light blue on Figure 4). These cells generate the dorsal most epidermis including the dCENs as well as the aBTN and one muscle cell $[82,90]$. The pBTN arises from the b-line cell just posterior to the b6.5 lineage cells (Figure 4a) [82]. In contrast, the ventral CENs arise far from the neural plate (Figure 4a, lower panel) [90]. The mechanisms of CEN specification are well elucidated but will not be discussed here [90-93].

Recently, a specialised region of the ascidian embryo, termed the neural border based on coexpression of vertebrate neural plate border genes such as Msx and Snail, has been described [82]. This territory includes the lateral-most cells of the a-line-derived neural plate, the b-line CNS precursors and the b-line epidermis that surrounds the lateral and posterior neural plate (Figure 4b). Some of these cells will generate part of the CNS, such as the pigmented cells and dorsal neural tube; others will generate specialised regions of epidermis with their associated PNS neurons (Figure 4) $[9,14,36,82,90]$. This lateral and posterior border region is proposed to have evolved from border cells already present in the common ancestor of tunicates and vertebrates (called the olfactore), which then evolved to give rise to the neural crest in the vertebrate lineage $[36,82]$.

\section{STEP-BY-STEP CELL FATE SPECIFICATION IN THE CNS}

In the following section, our current knowledge of the step-by-step specification of the CNS will be described. It will start with neural induction at the 32-cell stage of development. Developmental events prior to the 32-cell stage have been reviewed elsewhere [94-97]. Deciphering the mechanisms of cell fate specification was greatly assisted by the prior documentations of the cell lineages $[9,12-$ $15,25]$ and extensive efforts to build EST collections and gene expression profiles [13,29,98-102]. 


\section{Neural fate segregation}

\section{Segregation of the a-line neural lineages}

The a-line neural lineages start to become fate restricted at the 32-cell stage of development with the birth of the a6.5 cell, which will generate the medial columns 1-2 of rows III-VI and begins to express the Otx gene (Figure 2). This is considered as the first step of ascidian 'neural induction', though these cells will actually contribute to both sensory vesicle and the anterior neural border (see above). Induction of Otx in a6.5 depends upon Fgf9/16/20-signals arising from underlying vegetal cells [103]. Fgf9/16/20 acts through the MAP kinase kinase, MEK, resulting in dual phosphorylation of the MAP kinase, ERK1/2, which in turn leads to transcriptional activation of Otx via the ETS1/2 and Gata4/5/6 (formally GATAa) transcription factors $[103,104]$. Broadly available Fgf9/16/20 signals are antagonised by both ephrin and TGF $\beta$ signals [105]. The selection of neural precursors among the animal (=ectodermal) cells depends upon the ratio of their cell surface contact with inducing vegetal cells ( Fgf9/16/20-expressing) compared to their area of cell surface contact with inhibitory animal cells (Efna.d-expressing, formally ephrin-Ad) [105-107]. At the 64-cell stage, the lateral a-line neural plate precursors are segregated from epidermal fate to give rise to one row of six cells (Figure 2e). When these six cells divide along the anterior-posterior (A-P) axis during the generation of the 112cell stage embryo, an important cell fate segregation takes place: the separation of CNS neural plate precursors (row III/IV) from the non-CNS anterior neural plate precursors (row V/VI) (Figure 2f). This fate segregation also involves FGF signals, with FGF-ERK signalling promoting CNS over nonCNS fate and resulting in Zic-related.b (Zic-r.b, formally ZicL) expression in CNS precursors and Foxc in non-CNS precursors (Figure 5a) [108]. Thus, FGF signals govern the first two neural segregation steps, 'neural induction' and CNS specification. During the first step of neural induction, the neural precursors are prevented from precociously adopting the CNS neural fate (Zic-r.b+) by a repressive timer mechanism. This mechanism involves a set of three factors- two zinc finger proteins (BZ1 and 2) and Hes- $a$ transcription factor [109]. These molecules prevent neural precursors from adopting a precocious Zic-r.b-positive CNS neural fate in response to FGF-signals. The competence delay mechanism itself is switched off by auto-repression from the BZ factors. This simple 'feedback delay timer' mechanism explains how the response to FGF-signals differs in the same cell lineage at these two developmental stages. By the early gastrula stage, the a-line neural plate precursors consist of two rows of cells, six CNS precursors (the precursors of rows III and IV) and six non-CNS anterior neural plate precursors (the precursors of rows V and VI) (Figure 2f). These mechanisms of a-line neural fate segregation have also recently been reviewed elsewhere [97]. Maintenance of induced aline neural fate (including both CNS and non-CNS neural plate derivatives) depends upon gap junctions (connexin) [45,87] 


\section{Segregation of the b-line neural lineages}

Neural induction in the b-lineages takes place in parallel to a-lineages and involves similar mechanisms. As well as Otx, Nodal is also induced in the b6.5 neural precursors by FGF-signals at the 32-cell stage (Figure 2d) [91,103,110,111]. The differential activation of Nodal by FGF in b- but not a-line cells, is governed by Foxa.a (formally FoxAa) [91,112]. Foxa.a is expressed in all a- line cells where it blocks transcriptional activation of Nodal. How Foxa.a is differentially activated between aand b-lineages is not yet clear, though the ooplasmic segregation at the one-cell stage that establish differences across the Aa-Bb axis are likely to be involved $[95,96]$. Nodal and Otx are required for b6.5 lineage specification; both the dorsal neural tube and dorsal epidermis are lost when Nodal or Otx function is inhibited $[91,111]$. By the early gastrula stage, two cell divisions of the b6.5 lineage have resulted in the segregation of the CNS lineages from the lateral non-CNS border lineages (Figure 2df). At the 6-row neural plate stage, the b-lineages divide along the anterior-posterior axis. Whether the posterior-most b-lineage (pale green in Figure $2 \mathrm{f}-\mathrm{g}$ ) contributes to the neural tube is not agreed upon $[9,12,14]$. The mechanisms leading to $b$-line neural fate segregation have not yet been addressed.

\section{Segregation of the A-line neural lineages}

At the 64-cell stage the A-line neural lineages segregate from notochord lineages (Figure 2e). This fate segregation also involves differential FGF/ERK activation, but in contrast to neural induction in the aand b-line neural lineages, FGF-signals have an opposite effect. In the A-lineages, FGF-signals promote notochord and repress neural fates [113-115]. Indeed, the neural precursors require protection from FGF-signals via Efna.d signalling [116,117]. In the absence of ephrin-signalling neural precursors instead adopt notochord fate. The four A-line neural precursors of the 64-cell stage embryo then divide along the medial-lateral axis to generate one row of eight cells at the early gastrula stage (Figure 2f). This row of cells then divides along the anterior-posterior axis to generate rows I and II of the 6-row neural plate with the lateral most pair of cells giving rise to one CNS and one muscle precursor (Figure 2g).

\section{Neural plate patterning}

\section{Differential ERK1/2 activity patterns the neural plate along the A-P axis}

By the early gastrula stage, CNS precursors are arranged in two rows of precursors, one row of eight A-line cells and one row of six a-line cells (Figure 2f). These cells divide along the A-P axis to give 
rise to two rows of A-line and two rows of a-line CNS precursors at the '6-row neural plate' stage (termed '6-row in the literature since it also includes two rows of non-CNS anterior neural plate cells) (Figure 2g). Differential ERK1/2 activation between rows III (ERK1/2 on) and IV (ERK1/2 off) again governs their binary fate choice (Figure 5a) [118,119]. It is not yet clear how this differential activation pattern of ERK1/2 is achieved, though it is most likely explained, at least in part, by the expression pattern of $F g f$ genes [118,120-122]. Differential ERK1/2 activity is continuously observed in a-line cells following their successive A-P oriented cell divisions (Figure 5a). Its role during the specification of the pigment cells will be discussed later. Similarly, in the A-line cells of the 6-row neural plate stage embryo, differential ERK1/2 activation between row I $[118,119]$ (ERK1/2 on) and II (ERK1/2 off) is required for the binary fate choice of each sister cell pair (Figure 6) [121].

\section{Medial-Lateral neural plate patterning}

Independently of the ERK-dependent anterior-posterior patterning, Nodal and Delta-Notch signals pattern the neural plate across the medial-lateral axis. This patterning is best understood for the A-linederived part of the 6-row stage neural plate (Figure 6). By the 6-row neural plate stage, each cell within the A-line neural plate expresses a unique genetic signature $[11,121]$. Patterning of these cells along the medial-lateral axis is initiated by Nodal. The Nodal gene is activated in the b6.5 lineage of the 32-cell stage embryo during neural induction, as described above. Nodal signals subdivide the Aline neural lineages into medial and lateral domains (Figure 6a) $[91,110,121,123]$. This lineage segregation appears to operate in a binary mode with Nodal promoting lateral at the expense of medial fate $[91,110,121,123,124]$. One transcriptional target of Nodal signals, Snail, which encodes a transcription factor that is expressed in the lateral domain of the A-line derived neural plate, mediates the Nodal-dependent repression of medial neural plate genes [91,124]. In parallel, Nodal induces expression of Delta-like (previously Delta2 or Delta.b), in the b6.5 derivatives as well as a vegetally derived cell, at the 64-cell stage. Delta/Notch signals then act to induce column 4 identity (Figure 6a) [121]. Interestingly, this fate specification may not be binary; while Delta/Notch induces column 4 identity, it may not supress column 3 gene expression in column 4, although results concerning column 3 gene expression were inconsistent between different studies [11,121]. Again in a Nodaldependent fashion, expression of Delta-like is subsequently induced in columns 3 and 4 of the early gastrula stage embryo, where it acts to segregate column 2 from column 1 fates (Figure 6a) [121]. This patterning cascade, initiated by Nodal signalling at the 32-cell stage, is sufficient to divide the neural plate into its four distinct columns of differential gene expression (Figure 6). Together with the anterior-posterior patterning driven by differential FGF-ERK signalling, each cell in the A-line neural plate receives a unique combination of signalling inputs, which determine the eight unique cell identities present in the posterior neural plate (Figure 6b). The anterior-posterior (A-P) and medial- 
lateral (M-L) mechanisms are independent processes; the specific coordinates along the rows (A-P) or columns (M-L) of neural plate cells are not affected when patterning along the other axis is inhibited [121]. Importantly, where tested, it has been shown that disruption of this early patterning translates into predictable mis-specification of cell fates in the CNS at tailbud stages of development $[91,110,124]$.

Nodal is similarly required for the medio-lateral patterning of the anterior (a-line-derived) neural plate. Genes expressed in the lateral a-line neural plate are lost when Nodal signalling is inhibited [91,110]. In conclusion, establishment of the neural identities in the grid-like array of neural plate cells up to the 6-row neural plate is well understood, particularly for the A-lineages. However, further work is required to clarify the mechanisms that pattern the a-lineages and for many aspects of the b-lineages, which remain poorly characterised.

\section{From Neural plate to tailbud stages}

As described above, a unique combinatorial input of Nodal, Delta and FGF-ERK signalling confers a distinct cell identity upon each cell of the posterior (A-line derived) neural plate. These signal inputs initiate regional GRNs that further pattern the neural plate during the following developmental stages [11]. While the GRNs and subsequent patterning events that generate the fully patterned CNS are incompletely understood, a few cases have been particularly well elucidated and are described below. The first two cases are concerned with certain A-line neural plate cells. The lineages of these cells from the 6-row neural plate stage until the birth of the five pairs of post-mitotic cholinergic trunk ganglion neurons are described in Figure 7.

\section{Establishment of the sensory vesicle-neck boundary}

Fgf8/17/18 is expressed in A9.30 (induced by the Nodal+/Delta-/ERK1/2- combination) (Figure 8a). Fgf8/17/18-signals from A9.30 pattern the adjacent A9.16 lineage when it divides along the A-P axis. While A9.30 and A9.16 cells are side by side at the 6-row neural plate stage, the A9.30 daughter cells come to lie posterior to the daughter cells of A9.16 during the morphogenetic movements of neurulation (Figure 7) [12]. The A9.30 lineage contributes to the lateral wall of trunk ganglion. The A9.16 cell divides into A10.32 (anterior) which generates cells of the posterior sensory vesicle and A10.31 (posterior) which generates cells of the neck [9,11]. Fgf8/17/18 induces neck over posterior sensory vesicle fate in these daughters by inducing expression of Pax2/5/8a in A10.31 derivatives. Pax2/5/8a in turn induces Gli, Fgf9/16/20 and Arix, and represses Otx and Foxb (Figure 8b) [11]. 
Fgf8/17/18 thus establishes the gene expression boundary between the sensory vesicle and the neck of the neural tube.

\section{Column 3 of the A-line neural plate and the central pattern generator}

The column 3 cells of the A-line derived neural plate (A9.30, A9.29) will generate the ventral cholinergic neurons of the trunk ganglion as well as the ACIN neurons of the tail nerve cord, which together constitute the major components of the putative central pattern generator (Figure 7, 9) $[9,33-$ 35]. As discussed above, the trunk ganglion contains five pairs of ventral cholinergic neuronsA12.239, A.13.474, A11.118, A11.117 and A10.57, which each express different genetic markers and have distinct neuronal characteristics (Figure 2a, 9)[73]. The Efna.b-expressing A9.29 cell, specified in response to the combinatorial signal input of Nodal+/Delta-/ERK+, divides along the A-P axis into the post-mitotic A10.57 cholinergic motoneuron (Islet+/Mnx+) and A10.58 (Figure 9)[9]. The A10.58lineage will generate the ACIN neurons of the tail nerve cord [35]. Differential specification of these two lineages may involve differential ERK1/2 activity since pharmacological inhibition of MEK results in ectopic Mnx expression in A10.58 lineage cells [39]. The anterior-most four cholinergic neurons are generated from the $F g f 8 / 17 / 18$-expressing A9.30 cell (Nodal+/Delta-/ERK1/2-) of the neural plate (Figure 9) $[9,73]$. Antagonistic FGF-ephin signals and Delta-Notch signalling act to specify these four cells along the A-P axis: modulation of these signals results in cell fate transformations revealed by both changes in gene expression and neuronal characteristics $[39,73]$. The model proposed to explain the specification of these anterior four pairs of cholinergic neurons is summarised as follows (Figure 9) [39,73]. All divisions take place along the A-P axis. A9.30 divides into A10.60 (a) and A10.59 (p). The FGF/MEK/ERK cascade is activated only in the anterior daughter, being attenuated in the posterior daughter by antagonistic ephrin signals from the posterior neighbouring cell, A10.58. Following the next round of cell division, ERK is active in both daughters of A10.60 (A11.120 and A11.119) and the anterior daughter of A10.59 (A11.118), but is again attenuated in the posterior daughter, A11.117, by ephrin signals. A11.118 and A11.117 become postmitotic and adopt distinct neuronal fates due to this differential ERK activation. Delta-like is expressed in the A10.59 lineage (being repressed in its sister lineage, A10.60, by ERK activity). Deltalike activates the Notch signalling pathway in the posterior daughter of A10.60 (A11.119), leading to repression of $P a x 3 / 7$ expression. The A11.119 lineage undergoes two further divisions to generate non-neuronal Sox 1/2/3+(formally SoxB1) cells and the Vsx+ cholinergic interneuron (Figure 9). The mechanisms controlling the lineage segregation during these two final divisions are not yet determined. In the Pax3/7+ A11.120 lineage, following the subsequent cell division, differential ERK activation is once again required to determine the fate choice between the anterior daughter cell, A12.240 (Pax3/7+, Sox1/2/3+ non neuronal cell), and the posterior daughter cell, A12.239 (Pax3/7+, 
$D m b x+$ cholinergic interneuron), such that ERK activity is associated with the anterior daughter. The exact mechanisms underlying this differential ERK activation are not yet clear, though it involves Notch-Delta signalling [39]. Thus, we now have a detailed framework describing the step-by-step specification, following every cell division, from neural fate specification all the way to the formation of these post-mitotic trunk ganglion cholinergic neurons. How cholinergic character is imposed on these trunk ganglion neurons is also beginning to be elucidated. Expression of cholinergic genes depends upon $E b f$ (formally COE), which itself depends upon Neurogenin [11,125]. Both Ebf and Neurogenin are expressed in the cholinergic precursors during tailbud stages (though this is not so clear for Ebf expression in the A13.474 lineage) [11,73].

\section{Specification of the otolith and ocellus pigmented cells}

The pigment cell lineage is also well-described (Figure 5a). Pigment cells most likely share an evolutionary relationship with the cephalic neural crest of vertebrates [36] (for more discussion on evolutionary relationships of pigmented cells, see Esposito et al, 2015 [56]). Pigment cells arise from the lateral-most a-line derived CNS. From the 64-cell stage of development, a-line cells undergo four rounds of A-P oriented cell division. Following each division, the pigment cell lineage invariantly segregates with the posterior daughter and in each case the posterior daughter cell shows a higher level of ERK1/2 activation, such that ERK1/2 is continuously required during this period for the correct specification of the pigment cells (Figures 5a) $[108,118,119,122]$. ERK1/2 is most likely activated by FGF-signalling and mediated by ETS transcription factors at each stage $[36,119,120]$. The cell divisions up to the 6-row stage have been described above. From the 6-row stage, the cells in rows III (and IV) divide along the A-P axis to give row IIIa (anterior) and row IIIp (posterior) cells, with ERK1/2 active in row IIIp (as well as IVp) $[118,119]$. At this stage, but not at earlier stages, ephrin signals are required to attenuate ERK activation in anterior daughter cells [118]. Inhibition of this ephrin signalling results in supernumerary pigment cell formation [118]. The lateral row IIIp pigment cell lineage undergoes one final division and again the posterior daughter, now the post-mitotic pigment cell precursor, exhibits higher levels of ERK1/2 activation $[118,119]$. The post-mitotic pigment cell precursor pair (one from each side of the embryo) forms an equivalence group that needs to undergo one final cell fate choice, whether to become the otolith or the ocellus pigment cell [126]. Recent evidence suggests that this final fate choice is directed by Wnt signalling [36,122]. The FGFERK-ETS cascade induces $T c f$, a DNA-binding factor known to mediate canonical Wnt signals, in the pigment cell precursors, which then intercalate at the midline in a random fashion, with one cell posterior and one anterior $[122,126]$. Wnt7, expressed along the dorsal midline of the neural tube, just posterior to the pigment cell precursors, induces ocellus over otolith fate in the posteriorly-positioned pigment cell precursor (Figure 5a) [36]. 
While we know in detail the signalling requirements for pigment cell specification, it is not clear how the spatial pattern of ERK1/2 activation is achieved. In addition, the gene regulatory network acting downstream of ERK1/2 at each stage of pigment cell specification remains to be unravelled. The comprehensive description of gene expression profiles of the pigment cell lineage at each stage of their specification [119] will undoubtedly provide a rich resource to tackle this question.

\section{Photoreceptors of the ocellus- Left-Right brain patterning}

Once specified in the midline, the ocellus pigment cell moves to the right of the sensory vesicle, a movement that depends upon Nodal, which is expressed in the left epidermis of tailbud stage embryos (Figure 5b) [9,127]. In Ciona, the photoreceptors associated with the ocellus are reported to derive from the right-hand a9.33 and a9.37 lineage (row III medial two columns), with the coronet cells arising from the left hand lineage [9]. However, recent evidence suggests that the photoreceptors derive not from the a-line, but from the row II A-line cells [120]. An A-line origin would be in agreement with the photoreceptor cell lineage described in Halocynthia, in which lineage tracing showed that the photoreceptors arise from the right A8.7-lineage [14]. The cell lineage of the photoreceptors in Ciona thus requires clarification. Specification of the ocellus-associated photoreceptor lineages involves a Neurogenin-to-Onecut-to-Rx genetic cascade with Rx then activating Arrestin and Opsin1 gene expression [63,128,129]. Nodal expression on the left side of the larvae represses $R x$ gene expression (and thus Arrestin and Opsin1), restricting photoreceptor cell formation to only the right side (Figure 5b) [127]. Inhibition of Nodal signalling from late neurula stages (i.e. much later than the patterning role in the neural plate described above), results in photoreceptor formation on both sides of the ocellus as well as symmetrical pigmentation of the ocellus (Figure 5b) [127].

Our understanding of the cell lineage and how the majority of the sensory vesicle cell types are specified is incomplete, hampered by the relative complexity of this region. A transcriptomic analysis of the sensory vesicle should help build a gene expression map of the larval brain $[29,102]$. This could pave the way to elucidate further the patterning mechanisms and underlying GRNs, which in turn needs to be linked to the cell lineage and the different cell types found in the sensory vesicle.

\section{MORPHOGENESIS}

In order to understand how a functional CNS is constructed, we need to understand the morphogenetic processes of neural tube formation and how these processes are coordinated with the patterning mechanisms described above. For example, how the successive rounds of A-P oriented cell divisions 
that are observed in the ascidian neural lineages are controlled is not understood $[12,13]$. On the other hand, the mechanisms controlling the morphogenetic processes of neural tube closure have begun to be elucidated. Neural tube formation begins with the invagination of the neural plate along a posteriorto-anterior wave, followed by neural tube closure, which also takes place progressively in a posteriorto-anterior direction following a zipper-like closure $[12,13,130,131]$. This simple continuous closure is in contrast to more complex vertebrate models where closure initiates at multiple specific sites along the neural folds and zippering progresses in both anterior and posterior directions [17]. In ascidians it was shown that zippering involves local and sequential actomyosin-dependent contraction of the neural-epidermal cell junction just ahead of the advancing zipper, followed by junction exchange (neural-epidermal cell junctions are replaced by epidermal-epidermal and neural-neural cell junctions) and detachment of the cells from the zipper [130]. The epidermis also plays a critical role in the rolling up of the neural plate [132]. In ascidians, an extended G2 phase of the epidermal cell cycle is critical for neural tube formation [131]. During this pause in the cell cycle, ROCK (Rho-kinase)-dependent elongation of epidermal cells towards the midline contributes to closure of the neural furrow. If this extended G2 phase is experimentally reduced, elongation of epidermal cells towards the midline does not occur, posterior zipper initiation fails and the neural cells remain in a sheet [131]. Interestingly, while the posterior neural tube uses a zippering mechanism to close, the anterior neural tube closure appears to follow a 'purse string' contraction [130]. Anterior neural tube closure has not been studied in detail in Ciona, though it appears to depend upon Ascidian Cell Adhesion Molecule (ACAM) [133]. Sealing of the anterior neural folds at the end of neurulation depends upon T-type calcium channels and down-regulation of ephrin-Eph signalling, though the exact mechanism is not understood [134]. An anion transporter, soluble carrier 26 (Slc26a $\alpha$ ), and an ammonium transport protein (ATM1a) are required for the correct formation of the lumen of the sensory vesicle $[135,136]$. Thus, the morphogenetic processes of neurulation and how it is controlled are beginning to be tackled, though there still remains much to be understood.

\section{Conclusion}

As described above, in recent years much progress has been made towards our understanding of how this tiny and simple chordate CNS is constructed. Impressive amounts of EST and gene expression profiles have been compiled and the genetic mechanisms leading to induction and patterning of the central nervous system have begun to emerge. Many neuronal cell types have been described in the CNS and information on neurotransmitter distribution has been obtained. In some cases, we now have a very good conceptual framework of how specific neural cell types are generated in step-by-step manner (the cholinergic neurons of the trunk ganglion constituting the best example). In the vast 
majority of cases described, cell fate decisions are binary. The morphogenetic processes that roll the neural plate into a neural tube have also begun to be elucidated.

One of the main challenges ahead will be to integrate the gene expression patterns, neuronal cell types and cell lineages into a comprehensive larval body atlas. This is essential if we aim to gain a step-by-step molecular understanding of how each individual neural cell type is generated.

Unravelling the complete underlying GRN will be technically challenging given that many of the factors involved will have both early and late roles in development. However, the ability to conduct lineage-specific and temporal specific gene perturbation should help circumvent this problem. Methods such as electroporation to generate lineage specific expression of dominant negative constructs [39,119] or gene knockout constructs (such as CRISPR/Cas9) [8], as well as temporal application of chemical inhibitors of signalling pathways $[118,121,127]$ will no doubt continue to help achieve this aim. Our understanding of the neuronal network (connectome) is also currently very incomplete and will be essential to understand how the nervous system functions. Elucidating neuronal functions also remains a challenge. Optogenetic stimulation could potentially be used to assay the function of individual neurons or neuronal subtypes in larvae, as has been achieved for the cholinergic neurons of juveniles [41]. Finally, the morphogenetic processes that help build the larval CNS and how these processes are integrated into the GRNs remains to be understood. While the cell division patterns in the neural tissue are well described, how they are temporally controlled and oriented is not understood. The complex, multifaceted nature (multigenic, epigenic and environmental) of factors required for correct neural tube closure means that the genetic control of neurulation remains poorly understood in vertebrates despite decades of effort $[17,132,137]$. The simplicity of the ascidian model could make it a particularly amenable system to study the genetic control of neurulation. In conclusion the simplicity of the ascidian tadpole offers an opportunity to understand in precise detail the development and function of its miniature chordate CNS.

\section{References}

1. Satoh N, Rokhsar D, Nishikawa T. Chordate evolution and the three-phylum system. Proc Biol Sci. 2014;281: 20141729. doi:10.1098/rspb.2014.1729

2. Delsuc F, Brinkmann H, Chourrout D, Philippe H. Tunicates and not cephalochordates are the closest living relatives of vertebrates. Nature. 2006;439: 965-968. doi:10.1038/nature04336

3. Caputi L, Andreakis N, Mastrototaro F, Cirino P, Vassillo M, Sordino P. Cryptic speciation in a model invertebrate chordate. Proc Natl Acad Sci USA. 2007;104: 9364-9369.

doi:10.1073/pnas.0610158104

4. Pennati R, Ficetola GF, Brunetti R, Caicci F, Gasparini F, Griggio F, et al. Morphological Differences between Larvae of the Ciona intestinalis Species Complex: Hints for a Valid 
Taxonomic Definition of Distinct Species. PLoS ONE. 2015;10: e0122879. doi:10.1371/journal.pone.0122879

5. Sato A, Satoh N, Bishop JDD. Field identification of "types" A and B of the ascidian Ciona intestinalis in a region of sympatry. Mar Biol. 2012;159: 1611-1619. doi:10.1007/s00227-012$1898-5$

6. Lemaire P. Evolutionary crossroads in developmental biology: the tunicates. Development. 2011;138: 2143-2152. doi:10.1242/dev.048975

7. Sasaki H, Yoshida K, Hozumi A, Sasakura Y. CRISPR/Cas9-mediated gene knockout in the ascidian Ciona intestinalis. Dev Growth Differ. 2014;56: 499-510. doi:10.1111/dgd.12149

8. Stolfi A, Gandhi S, Salek F, Christiaen L. Tissue-specific genome editing in Ciona embryos by CRISPR/Cas9. Development. 2014;141: 4115-4120. doi:10.1242/dev.114488

9. Cole AG, Meinertzhagen IA. The central nervous system of the ascidian larva: mitotic history of cells forming the neural tube in late embryonic Ciona intestinalis. Dev Biol. 2004;271: 239262. doi:10.1016/j.ydbio.2004.04.001

10. Ikuta T, Saiga H. Dynamic change in the expression of developmental genes in the ascidian central nervous system: revisit to the tripartite model and the origin of the midbrain-hindbrain boundary region. Dev Biol. 2007;312: 631-643. doi:10.1016/j.ydbio.2007.10.005

11. Imai KS, Stolfi A, Levine M, Satou Y. Gene regulatory networks underlying the compartmentalization of the Ciona central nervous system. Development. 2009;136: 285-293. doi:10.1242/dev.026419

12. Nicol D, Meinertzhagen IA. Development of the central nervous system of the larva of the ascidian, Ciona intestinalis L. II. Neural plate morphogenesis and cell lineages during neurulation. Dev Biol. 1988;130: 737-766.

13. Nicol D, Meinertzhagen IA. Development of the central nervous system of the larva of the ascidian, Ciona intestinalis L. I. The early lineages of the neural plate. Dev Biol. 1988;130: 721-736.

14. Nishida H. Cell lineage analysis in ascidian embryos by intracellular injection of a tracer enzyme. III. Up to the tissue restricted stage. Dev Biol. 1987;121: 526-541.

15. Taniguchi $\mathrm{K}$, Nishida $\mathrm{H}$. Tracing cell fate in brain formation during embryogenesis of the ascidian Halocynthia roretzi. Dev Growth Differ. 2004;46: 163-180. doi:10.1111/j.1440169X.2004.00736.x

16. Lemaire P, Smith WC, Nishida H. Ascidians and the plasticity of the chordate developmental program. Curr Biol. 2008;18: R620-631. doi:10.1016/j.cub.2008.05.039

17. Copp AJ, Greene NDE. Neural tube defects-disorders of neurulation and related embryonic processes. WIREs Dev Biol. 2013;2: 213-227. doi:10.1002/wdev.71

18. Katz MJ. Comparative Anatomy of the Tunicate Tadpole, Ciona Intestinalis. Biol Bull. 1983;164: 1-27.

19. Dufour HD, Chettouh Z, Deyts C, de Rosa R, Goridis C, Joly J-S, et al. Precraniate origin of cranial motoneurons. Proc Natl Acad Sci USA. 2006;103: 8727-8732.

doi:10.1073/pnas.0600805103 
20. Wada H, Saiga H, Satoh N, Holland PW. Tripartite organization of the ancestral chordate brain and the antiquity of placodes: insights from ascidian Pax-2/5/8, Hox and Otx genes. Development. 1998;125: 1113-1122.

21. Hudson C, Ba M, Rouvière C, Yasuo H. Divergent mechanisms specify chordate motoneurons: evidence from ascidians. Development. 2011;138: 1643-1652. doi:10.1242/dev.055426

22. Ikuta T, Satoh N, Saiga H. Limited functions of Hox genes in the larval development of the ascidian Ciona intestinalis. Development. 2010;137: 1505-1513. doi:10.1242/dev.046938

23. Sobral D, Tassy O, Lemaire P. Highly divergent gene expression programs can lead to similar chordate larval body plans. Curr Biol. 2009;19: 2014-2019. doi:10.1016/j.cub.2009.10.036

24. Stolfi A, Sasakura Y, Chalopin D, Satou Y, Christiaen L, Dantec C, et al. Guidelines for the nomenclature of genetic elements in tunicate genomes. Genesis. 2015;53: 1-14. doi: $10.1002 / \mathrm{dvg} .22822$

25. Conklin EG. The organisation and cell lineage of the ascidian egg. J Acad Natl Sci (Philadelphia). 13th ed. 1905: 1-119.

26. Imai KS, Satoh N, Satou Y. Region specific gene expressions in the central nervous system of the ascidian embryo. Mech Dev. 2002;119 Suppl 1: S275-277.

27. Takahashi T, Holland PWH. Amphioxus and ascidian Dmbx homeobox genes give clues to the vertebrate origins of midbrain development. Development. 2004;131: 3285-3294.

doi:10.1242/dev.01201

28. Wada H, Satoh N. Patterning the protochordate neural tube. Curr Opin Neurobiol. 2001;11: 1621.

29. Hamada M, Shimozono N, Ohta N, Satou Y, Horie T, Kawada T, et al. Expression of neuropeptide- and hormone-encoding genes in the Ciona intestinalis larval brain. Dev Biol. 2011;352: 202-214. doi:10.1016/j.ydbio.2011.01.006

30. Moret F, Christiaen L, Deyts C, Blin M, Vernier P, Joly J-S. Regulatory gene expressions in the ascidian ventral sensory vesicle: evolutionary relationships with the vertebrate hypothalamus. Dev Biol. 2005;277: 567-579. doi:10.1016/j.ydbio.2004.11.004

31. Moret F, Christiaen L, Deyts C, Blin M, Joly J-S, Vernier P. The dopamine-synthesizing cells in the swimming larva of the tunicate Ciona intestinalis are located only in the hypothalamusrelated domain of the sensory vesicle. Eur J Neurosci. 2005;21: 3043-3055. doi:10.1111/j.1460-9568.2005.04147.x

32. Razy-Krajka F, Brown ER, Horie T, Callebert J, Sasakura Y, Joly J-S, et al. Monoaminergic modulation of photoreception in ascidian: evidence for a proto-hypothalamo-retinal territory. BMC Biol. 2012;10: 45. doi:10.1186/1741-7007-10-45

33. Horie T, Nakagawa M, Sasakura Y, Kusakabe TG, Tsuda M. Simple motor system of the ascidian larva: neuronal complex comprising putative cholinergic and GABAergic/glycinergic neurons. Zool Sci. 2010;27: 181-190. doi:10.2108/zsj.27.181

34. Nishino A, Okamura Y, Piscopo S, Brown ER. A glycine receptor is involved in the organization of swimming movements in an invertebrate chordate. BMC Neurosci. 2010;11: 6. doi:10.1186/1471-2202-11-6 
35. Nishitsuji K, Horie T, Ichinose A, Sasakura Y, Yasuo H, Kusakabe TG. Cell lineage and cisregulation for a unique GABAergic/glycinergic neuron type in the larval nerve cord of the ascidian Ciona intestinalis. Dev Growth Differ. 2012;54: 177-186.

36. Abitua PB, Wagner E, Navarrete IA, Levine M. Identification of a rudimentary neural crest in a non-vertebrate chordate. Nature. 2012;492: 104-107. doi:10.1038/nature11589

37. Corbo JC, Erives A, Di Gregorio A, Chang A, Levine M. Dorsoventral patterning of the vertebrate neural tube is conserved in a protochordate. Development. 1997;124: 2335-2344.

38. Takatori N, Satou Y, Satoh N. Expression of hedgehog genes in Ciona intestinalis embryos. Mech Dev. 2002;116: 235-238.

39. Stolfi A, Wagner E, Taliaferro JM, Chou S, Levine M. Neural tube patterning by Ephrin, FGF and Notch signaling relays. Development. 2011;138: 5429-5439. doi:10.1242/dev.072108

40. Horie T, Shinki R, Ogura Y, Kusakabe TG, Satoh N, Sasakura Y. Ependymal cells of chordate larvae are stem-like cells that form the adult nervous system. Nature. 2011;469: 525-528. doi:10.1038/nature09631

41. Hozumi A, Horie T, Sasakura Y. Neuronal map reveals the highly regionalized pattern of the juvenile central nervous system of the ascidian Ciona intestinalis. Dev Dyn. 2015;244: 13751393. doi:10.1002/dvdy.24317

42. Bone Q. On the locomotion of ascidian tadpole larvae. Journal of the Marine Biological Association of the United Kingdom. 1992;72: 161-186. doi:10.1017/S0025315400048864

43. Zega G, Thorndyke MC, Brown ER. Development of swimming behaviour in the larva of the ascidian Ciona intestinalis. J Exp Biol. 2006;209: 3405-3412. doi:10.1242/jeb.02421

44. Horie T, Nakagawa M, Sasakura Y, Kusakabe TG. Cell type and function of neurons in the ascidian nervous system. Development, Growth \& Differentiation. 2009;51: 207-220. doi:10.1111/j.1440-169X.2009.01105.x

45. Hackley C, Mulholland E, Kim GJ, Newman-Smith E, Smith WC. A transiently expressed connexin is essential for anterior neural plate development in Ciona intestinalis. Development. 2013;140: 147-155. doi:10.1242/dev.084681

46. Jiang D, Tresser JW, Horie T, Tsuda M, Smith WC. Pigmentation in the sensory organs of the ascidian larva is essential for normal behavior. J Exp Biol. 2005;208: 433-438. doi:10.1242/jeb.01420

47. Mast SO. Reactions to light in the larvae of the ascidians, Amaroucium constellatum and Amaroucium pellucidum with special reference to photic orientation. J Exp Zool. 1921;34: 148-187. doi:10.1002/jez.1400340204

48. Nakagawa M, Miyamoto T, Ohkuma M, Tsuda M. Action spectrum for the photophobic response of Ciona intestinalis (Ascidieacea, Urochordata) larvae implicates retinal protein. Photochem Photobiol. 1999;70: 359-362.

49. Svane IB, Young CM. The ecology and behaviour of ascidian larvae. Oceanogr Mar Biol Rev. : 45-90.

50. Tsuda M, Kawakami I, Shiraishi S. Sensitization and habituation of the swimming behavior in ascidian larvae to light. Zool Sci. 2003;20: 13-22. doi:10.2108/zsj.20.13 
51. Tsuda M, Sakurai D, Goda M. Direct evidence for the role of pigment cells in the brain of ascidian larvae by laser ablation. J Exp Biol. 2003;206: 1409-1417.

52. Nishino A, Baba SA, Okamura Y. A mechanism for graded motor control encoded in the channel properties of the muscle ACh receptor. Proc Natl Acad Sci USA. 2011;108: 25992604. doi:10.1073/pnas.1013547108

53. Ohmori H, Sasaki S. Development of neuromuscular transmission in a larval tunicate. J Physiol (Lond). 1977;269: 221-254.

54. Brown ER, Nishino A, Bone Q, Meinertzhagen IA, Okamura Y. GABAergic synaptic transmission modulates swimming in the ascidian larva. Eur J Neurosci. 2005;22: 2541-2548. doi:10.1111/j.1460-9568.2005.04420.x

55. Nicol D, Meinertzhagen IA. Cell counts and maps in the larval central nervous system of the ascidian Ciona intestinalis (L.). J Comp Neurol. 1991;309: 415-429.

doi:10.1002/cne.903090402

56. Esposito R, Racioppi C, Pezzotti MR, Branno M, Locascio A, Ristoratore F, et al. The ascidian pigmented sensory organs: structures and developmental programs. Genesis. 2015;53: 15-33. doi: $10.1002 / \mathrm{dvg} .22836$

57. Sakurai D, Goda M, Kohmura Y, Horie T, Iwamoto H, Ohtsuki H, et al. The role of pigment cells in the brain of ascidian larva. J Comp Neurol. 2004;475: 70-82. doi:10.1002/cne.20142

58. Dilly PN. Studies on the receptors in the cerebral vesicle of the ascidian tadpole. I. The otolith. Quart J micr Sci. 1962;103: 393-398.

59. Eakin R M, Kuda, A. Ultrastructure of Sensory Receptors in Ascidian Tadpoles. Z Zellforsch. 1971;112: 287-312.

60. Horie T, Kusakabe T, Tsuda M. Glutamatergic networks in the Ciona intestinalis larva. J Comp Neurol. 2008;508: 249-263. doi:10.1002/cne.21678

61. Torrence SA. Sensory endings of the ascidian static organ (Chordata, Ascidiacea). Zoomorphology. 1986;106: 61-66. doi:10.1007/BF00312108

62. Imai JH, Meinertzhagen IA. Neurons of the ascidian larval nervous system in Ciona intestinalis: I. Central nervous system. J Comp Neurol. 2007;501: 316-334.

doi: $10.1002 /$ cne. 21246

63. D'Aniello S, D'Aniello E, Locascio A, Memoli A, Corrado M, Russo MT, et al. The ascidian homolog of the vertebrate homeobox gene Rx is essential for ocellus development and function. Differentiation. 2006;74: 222-234. doi:10.1111/j.1432-0436.2006.00071.x

64. Horie T, Sakurai D, Ohtsuki H, Terakita A, Shichida Y, Usukura J, et al. Pigmented and nonpigmented ocelli in the brain vesicle of the ascidian larva. J Comp Neurol. 2008;509: 88102. doi:10.1002/cne. 21733

65. Inada K, Horie T, Kusakabe T, Tsuda M. Targeted knockdown of an opsin gene inhibits the swimming behaviour photoresponse of ascidian larvae. Neurosci Lett. 2003;347: 167-170.

66. Dilly PN. Studies on the receptors in the cerebral vesicle of the ascidian tadpole. 2. The ocellus. Quart J micr Sci. 1971;105: 13-20. 
67. Horie T, Orii H, Nakagawa M. Structure of ocellus photoreceptors in the ascidian Ciona intestinalis larva as revealed by an anti-arrestin antibody. J Neurobiol. 2005;65: 241-250. doi:10.1002/neu.20197

68. Takamura K, Minamida N, Okabe S. Neural map of the larval central nervous system in the ascidian Ciona intestinalis. Zool Sci. 2010;27: 191-203. doi:10.2108/zsj.27.191

69. Zega G, Biggiogero M, Groppelli S, Candiani S, Oliveri D, Parodi M, et al. Developmental expression of glutamic acid decarboxylase and of gamma-aminobutyric acid type B receptors in the ascidian Ciona intestinalis. J Comp Neurol. 2008;506: 489-505. doi:10.1002/cne.21565

70. Kusakabe T, Tsuda M. Photoreceptive systems in ascidians. Photochem Photobiol. 2007;83: 248-252. doi:10.1562/2006-07-11-IR-965

71. Shimeld SM, Purkiss AG, Dirks RPH, Bateman OA, Slingsby C, Lubsen NH. Urochordate betagamma-crystallin and the evolutionary origin of the vertebrate eye lens. Curr Biol. 2005;15: 1684-1689. doi:10.1016/j.cub.2005.08.046

72. Konno A, Kaizu M, Hotta K, Horie T, Sasakura Y, Ikeo K, et al. Distribution and structural diversity of cilia in tadpole larvae of the ascidian Ciona intestinalis. Dev Biol. 2010;337: 4262. doi:10.1016/j.ydbio.2009.10.012

73. Stolfi A, Levine M. Neuronal subtype specification in the spinal cord of a protovertebrate. Development. 2011;138: 995-1004. doi:10.1242/dev.061507

74. Pennati R, Candiani S, Biggiogero M, Zega G, Groppelli S, Oliveri D, et al. Developmental expression of tryptophan hydroxylase gene in Ciona intestinalis. Dev Genes Evol. 2007;217: 307-313. doi:10.1007/s00427-007-0138-3

75. Crowther RJ, Whittaker JR. Structure of the caudal neural tube in an ascidian larva: vestiges of its possible evolutionary origin from a ciliated band. J Neurobiol. 1992;23: 280-292. doi:10.1002/neu.480230307

76. Imai JH, Meinertzhagen IA. Neurons of the ascidian larval nervous system in Ciona intestinalis: II. Peripheral nervous system. J Comp Neurol. 2007;501: 335-352. doi: $10.1002 /$ cne. 21247

77. Takamura K. Nervous network in larvae of the ascidian Ciona intestinalis. Dev Genes Evol. 1998;208: 1-8.

78. Sotgia C, Fascio U, Melone G, De Bernardi F. Adhesive Papillae of Phallusia mamillata Larvae: Morphology and Innervation. Zoological Science. 1998;15: 363-370. doi:10.2108/zsj.15.363

79. Yokoyama TD, Hotta K, Oka K. Comprehensive morphological analysis of individual peripheral neuron dendritic arbors in ascidian larvae using the photoconvertible protein Kaede. Dev Dyn. 2014;243: 1362-1373. doi:10.1002/dvdy.24169

80. Crowther RJ, Whittaker JR. Serial repetition of cilia pairs along the tail surface of an ascidian larva. J Exp Zool. 1994;268: 9-16. doi:10.1002/jez.1402680103

81. Terakubo HQ, Nakajima Y, Sasakura Y, Horie T, Konno A, Takahashi H, et al. Network structure of projections extending from peripheral neurons in the tunic of ascidian larva. Dev Dyn. 2010;239: 2278-2287. doi:10.1002/dvdy.22361 
82. Stolfi A, Ryan K, Meinertzhagen IA, Christiaen L. Migratory neuronal progenitors arise from the neural plate borders in tunicates. Nature. 2015; doi:10.1038/nature15758

83. Nishida H, Satoh N. Cell lineage analysis in ascidian embryos by intracellular injection of a tracer enzyme. I. Up to the eight-cell stage. Dev Biol. 1983;99: 382-394.

84. Christiaen L, Jaszczyszyn Y, Kerfant M, Kano S, Thermes V, Joly J-S. Evolutionary modification of mouth position in deuterostomes. Semin Cell Dev Biol. 2007;18: 502-511. doi:10.1016/j.semcdb.2007.06.002

85. Veeman MT, Newman-Smith E, El-Nachef D, Smith WC. The ascidian mouth opening is derived from the anterior neuropore: reassessing the mouth/neural tube relationship in chordate evolution. Dev Biol. 2010;344: 138-149. doi:10.1016/j.ydbio.2010.04.028

86. Abitua PB, Gainous TB, Kaczmarczyk AN, Winchell CJ, Hudson C, Kamata K, et al. The prevertebrate origins of neurogenic placodes. Nature. 2015; doi:10.1038/nature14657

87. Deschet K, Smith WC. Frimousse - a spontaneous ascidian mutant with anterior ectodermal fate transformation. Current Biology. 2004;14: R408-R410. doi:10.1016/j.cub.2004.05.029

88. Hudson C, Yasuo H. Similarity and diversity in mechanisms of muscle fate induction between ascidian species. Biol Cell. 2008;100: 265-277. doi:10.1042/BC20070144

89. Ohtsuka Y, Matsumoto J, Katsuyama Y, Okamura Y. Nodal signaling regulates specification of ascidian peripheral neurons through control of the BMP signal. Development. 2014;141: 38893899. doi:10.1242/dev.110213

90. Pasini A, Amiel A, Rothbächer U, Roure A, Lemaire P, Darras S. Formation of the ascidian epidermal sensory neurons: insights into the origin of the chordate peripheral nervous system. PLoS Biol. 2006;4: e225. doi:10.1371/journal.pbio.0040225

91. Imai KS, Levine M, Satoh N, Satou Y. Regulatory blueprint for a chordate embryo. Science. 2006;312: 1183-1187. doi:10.1126/science.1123404

92. Roure A, Darras S. Msxb is a core component of the genetic circuitry specifying the dorsal and ventral neurogenic midlines in the ascidian embryo. Dev Biol. 2016;409: 277-287. doi:10.1016/j.ydbio.2015.11.009

93. Waki K, Imai KS, Satou Y. Genetic pathways for differentiation of the peripheral nervous system in ascidians. Nat Commun. 2015;6: 8719. doi:10.1038/ncomms9719

94. Kumano G, Nishida H. Ascidian embryonic development: an emerging model system for the study of cell fate specification in chordates. Dev Dyn. 2007;236: 1732-1747. doi:10.1002/dvdy.21108

95. Lemaire P. Unfolding a chordate developmental program, one cell at a time: invariant cell lineages, short-range inductions and evolutionary plasticity in ascidians. Dev Biol. 2009;332: 48-60. doi:10.1016/j.ydbio.2009.05.540

96. Nishida H. Specification of embryonic axis and mosaic development in ascidians. Dev Dyn. 2005;233: 1177-1193. doi:10.1002/dvdy.20469

97. Satou Y, Imai KS. Gene regulatory systems that control gene expression in the Ciona embryo. Proc Jpn Acad, Ser B, Phys Biol Sci. 2015;91: 33-51. doi:10.2183/pjab.91.33 
98. Imai KS, Hino K, Yagi K, Satoh N, Satou Y. Gene expression profiles of transcription factors and signaling molecules in the ascidian embryo: towards a comprehensive understanding of gene networks. Development. 2004;131: 4047-4058. doi:10.1242/dev.01270

99. Kusakabe T, Yoshida R, Kawakami I, Kusakabe R, Mochizuki Y, Yamada L, et al. Gene expression profiles in tadpole larvae of Ciona intestinalis. Dev Biol. 2002;242: 188-203. doi: 10.1006/dbio.2002.0538

100. Satou Y, Takatori N, Yamada L, Mochizuki Y, Hamaguchi M, Ishikawa H, et al. Gene expression profiles in Ciona intestinalis tailbud embryos. Development. 2001;128: 2893-2904.

101. Satou Y, Yamada L, Mochizuki Y, Takatori N, Kawashima T, Sasaki A, et al. A cDNA resource from the basal chordate Ciona intestinalis. Genesis. 2002;33: 153-154. doi:10.1002/gene.10119

102. Shimozono N, Ohta N, Satoh N, Hamada M. Differential Regional Expression of Genes in the Developing Brain of Ciona intestinalis Embryos. Zoological Science. 2010;27: 103-109. doi:10.2108/zsj.27.103

103. Bertrand V, Hudson C, Caillol D, Popovici C, Lemaire P. Neural tissue in ascidian embryos is induced by FGF9/16/20, acting via a combination of maternal GATA and Ets transcription factors. Cell. 2003;115: 615-627.

104. Hudson C, Darras S, Caillol D, Yasuo H, Lemaire P. A conserved role for the MEK signalling pathway in neural tissue specification and posteriorisation in the invertebrate chordate, the ascidian Ciona intestinalis. Development. 2003;130: 147-159.

105. Ohta N, Satou Y. Multiple signaling pathways coordinate to induce a threshold response in a chordate embryo. PLoS Genet. 2013;9: e1003818. doi:10.1371/journal.pgen.1003818

106. Ohta N, Waki K, Mochizuki A, Satou Y. A Boolean Function for Neural Induction Reveals a Critical Role of Direct Intercellular Interactions in Patterning the Ectoderm of the Ascidian Embryo. PLoS Comput Biol. 2015;11: e1004687. doi:10.1371/journal.pcbi.1004687

107. Tassy O, Daian F, Hudson C, Bertrand V, Lemaire P. A quantitative approach to the study of cell shapes and interactions during early chordate embryogenesis. Curr Biol. 2006;16: 345358. doi:10.1016/j.cub.2005.12.044

108. Wagner E, Levine M. FGF signaling establishes the anterior border of the Ciona neural tube. Development. 2012;139: 2351-2359. doi:10.1242/dev.078485

109. Ikeda T, Matsuoka T, Satou Y. A time delay gene circuit is required for palp formation in the ascidian embryo. Development. 2013;140: 4703-4708. doi:10.1242/dev.100339

110. Hudson C, Yasuo H. Patterning across the ascidian neural plate by lateral Nodal signalling sources. Development. 2005;132: 1199-1210. doi:10.1242/dev.01688

111. Roure A, Lemaire P, Darras S. An otx/nodal regulatory signature for posterior neural development in ascidians. PLoS Genet. 2014;10: e1004548. doi:10.1371/journal.pgen.1004548

112. Lamy C, Rothbächer U, Caillol D, Lemaire P. Ci-FoxA-a is the earliest zygotic determinant of the ascidian anterior ectoderm and directly activates Ci-sFRP1/5. Development. 2006;133: 2835-2844. doi:10.1242/dev.02448 
113. Imai KS, Satoh N, Satou Y. Early embryonic expression of FGF4/6/9 gene and its role in the induction of mesenchyme and notochord in Ciona savignyi embryos. Development. 2002;129: $1729-1738$.

114. Kim GJ, Nishida H. Role of the FGF and MEK signaling pathway in the ascidian embryo. Dev Growth Differ. 2001;43: 521-533.

115. Yasuo H, Hudson C. FGF8/17/18 functions together with FGF9/16/20 during formation of the notochord in Ciona embryos. Dev Biol. 2007;302: 92-103. doi:10.1016/j.ydbio.2006.08.075

116. Haupaix N, Stolfi A, Sirour C, Picco V, Levine M, Christiaen L, et al. p120RasGAP mediates ephrin/Eph-dependent attenuation of FGF/ERK signals during cell fate specification in ascidian embryos. Development. 2013;140: 4347-4352. doi:10.1242/dev.098756

117. Picco V, Hudson C, Yasuo H. Ephrin-Eph signalling drives the asymmetric division of notochord/neural precursors in Ciona embryos. Development. 2007;134: 1491-1497. doi: $10.1242 / \mathrm{dev} .003939$

118. Haupaix N, Abitua PB, Sirour C, Yasuo H, Levine M, Hudson C. Ephrin-mediated restriction of ERK1/2 activity delimits the number of pigment cells in the Ciona CNS. Dev Biol. 2014;394: 170-180. doi:10.1016/j.ydbio.2014.07.010

119. Racioppi C, Kamal AK, Razy-Krajka F, Gambardella G, Zanetti L, di Bernardo D, et al. Fibroblast growth factor signalling controls nervous system patterning and pigment cell formation in Ciona intestinalis. Nat Commun. 2014;5: 4830. doi:10.1038/ncomms5830

120. Gainous TB, Wagner E, Levine M. Diverse ETS transcription factors mediate FGF signaling in the Ciona anterior neural plate. Dev Biol. 2015; doi:10.1016/j.ydbio.2014.12.032

121. Hudson C, Lotito S, Yasuo H. Sequential and combinatorial inputs from Nodal, Delta2/Notch and FGF/MEK/ERK signalling pathways establish a grid-like organisation of distinct cell identities in the ascidian neural plate. Development. 2007;134: 3527-3537. doi: $10.1242 / \mathrm{dev} .002352$

122. Squarzoni P, Parveen F, Zanetti L, Ristoratore F, Spagnuolo A. FGF/MAPK/Ets signaling renders pigment cell precursors competent to respond to Wnt signal by directly controlling CiTcf transcription. Development. 2011;138: 1421-1432. doi:10.1242/dev.057323

123. Mita K, Fujiwara S. Nodal regulates neural tube formation in the Ciona intestinalis embryo. Dev Genes Evol. 2007;217: 593-601. doi:10.1007/s00427-007-0168-x

124. Hudson C, Sirour C, Yasuo H. Snail mediates medial-lateral patterning of the ascidian neural plate. Dev Biol. 2015;403: 172-179. doi:10.1016/j.ydbio.2015.04.026

125. Kratsios P, Stolfi A, Levine M, Hobert O. Coordinated regulation of cholinergic motor neuron traits through a conserved terminal selector gene. Nat Neurosci. 2012;15: 205-214. doi:10.1038/nn.2989

126. Nishida H, Satoh N. Determination and regulation in the pigment cell lineage of the ascidian embryo. Dev Biol. 1989;132: 355-367.

127. Yoshida K, Saiga H. Repression of Rx gene on the left side of the sensory vesicle by Nodal signaling is crucial for right-sided formation of the ocellus photoreceptor in the development of Ciona intestinalis. Dev Biol. 2011;354: 144-150. doi:10.1016/j.ydbio.2011.03.006 
128. D'Aniello E, Pezzotti MR, Locascio A, Branno M. Onecut is a direct neural-specific transcriptional activator of Rx in Ciona intestinalis. Dev Biol. 2011;355: 358-371. doi:10.1016/j.ydbio.2011.05.584

129. Pezzotti MR, Locascio A, Racioppi C, Fucci L, Branno M. Auto and cross regulatory elements control Onecut expression in the ascidian nervous system. Dev Biol. 2014;390: 273-287. doi:10.1016/j.ydbio.2014.03.011

130. Hashimoto H, Robin FB, Sherrard KM, Munro EM. Sequential contraction and exchange of apical junctions drives zippering and neural tube closure in a simple chordate. Dev Cell. 2015;32: 241-255. doi:10.1016/j.devcel.2014.12.017

131. Ogura Y, Sakaue-Sawano A, Nakagawa M, Satoh N, Miyawaki A, Sasakura Y. Coordination of mitosis and morphogenesis: role of a prolonged G2 phase during chordate neurulation. Development. 2011;138: 577-587. doi:10.1242/dev.053132

132. Colas JF, Schoenwolf GC. Towards a cellular and molecular understanding of neurulation. Dev Dyn. 2001;221: 117-145. doi:10.1002/dvdy.1144

133. Morales Diaz H, Mejares E, Newman-Smith E, Smith WC. ACAM, a novel member of the neural IgCAM family, mediates anterior neural tube closure in a primitive chordate. Developmental Biology. 2016;409: 288-296. doi:10.1016/j.ydbio.2015.10.032

134. Abdul-Wajid S, Morales-Diaz H, Khairallah SM, Smith WC. T-type Calcium Channel Regulation of Neural Tube Closure and EphrinA/EPHA Expression. Cell Rep. 2015;13: 829_ 839. doi:10.1016/j.celrep.2015.09.035

135. Deng W, Nies F, Feuer A, Bocina I, Oliver D, Jiang D. Anion translocation through an Slc26 transporter mediates lumen expansion during tubulogenesis. Proc Natl Acad Sci USA. 2013;110: 14972-14977. doi:10.1073/pnas.1220884110

136. Marino R, Melillo D, Di Filippo M, Yamada A, Pinto MR, De Santis R, et al. Ammonium channel expression is essential for brain development and function in the larva of Ciona intestinalis. J Comp Neurol. 2007;503: 135-147. doi:10.1002/cne.21370

137. Greene NDE, Copp AJ. Neural Tube Defects. Annual Review of Neuroscience. 2014;37: 221242. doi:10.1146/annurev-neuro-062012-170354

138. Tassy O, Dauga D, Daian F, Sobral D, Robin F, Khoueiry P, et al. The ANISEED database: digital representation, formalization, and elucidation of a chordate developmental program. Genome Res. 2010;20: 1459-1468. doi:10.1101/gr.108175.110

139. Munro EM, Odell GM. Polarized basolateral cell motility underlies invagination and convergent extension of the ascidian notochord. Development. 2002;129: 13-24.

\section{Acknowledgements}

The author is a CNRS researcher and works in the laboratory of Hitoyoshi Yasuo. I am grateful to $\mathrm{H}$. Yasuo for discussions and to Cathy Sirour and H. Yasuo for critical reading of the manuscript. Work 
in our laboratory is supported by Centre National de la Recherche Scientifique (CNRS), the Université Pierre et Marie Curie and the Fondation ARC.

Figure captions

Figure 1. Comparable fate maps between ascidians and vertebrates at the pre-gastrula stage. Lateral views of a Xenopus (frog) and ascidian embryo, with notochord forming side (traditionally termed 'dorsal') to the left. Adapted from ref [16], Copyright Elsevier.

Figure 2. Lineages of the central nervous system. (a) At the top is a photograph of a larval trunk and anterior part of the tail. The sensory vesicle is outlined with a dotted line. The two pigmented cells can clearly be seen (otolith anterior). The tail nerve cord, situated between the dorsal epidermis and notochord (No), is not visible due to its very small size. Below the photo is a drawing in lateral view of an ascidian larval CNS showing the sensory vesicle, neck, trunk ganglion and tail nerve cord. For illustration, the CNS has been greatly enlarged within the larvae. The tail is truncated in this and all subsequent figures. To the right of the larva is shown a transverse section of the tail showing the organisation of the nerve cord (coloured), muscles (M), notochord (No) and endoderm (E). Below the larva are gene expression domains in the CNS represented by bars and, on the right, the corresponding region of the vertebrate CNS. (a-g) Although ascidian embryos are conventionally drawn in either vegetal or animal view with anterior up, the embryos drawings here are all shown with anterior to the left to maintain consistency throughout the figure. Lineages are identical on each side of the bilaterally symmetrical embryo. The side from which the embryo is viewed is indicated. Sister cell relationships are indicated by bars connecting the cells. The colour code is: red- a-line lineage CNS-fate restricted; pink- a-line CNS lineages before fate restriction; grey- anterior non-CNS a-line neural plate; yellowmedial A-line neural plate derivatives; tan- lateral A-line neural plate derivatives; pale tan- A-line neural lineages before neural fate restriction; green- b-line CNS; pale green- b-line neural lineages before fate restriction. Note: posterior-lateral A-line 'CNS lineages' also contribute to muscle. For 
simplicity, this lineage is considered as 'neural fate restricted' here. The contribution of the posteriormost b-line (pale green in $\mathrm{f}-\mathrm{g}$ ) is not resolved $[9,12,14]$. An asterisk marks the anterior-most border of the CNS. Major events in CNS development are indicated below the drawings. The arrows on (d) indicate the FGF neural inducing signals. (g) On the right of the neural plate stage embryo drawing is a schematic representation of the neural plate. The neural plate is a grid-like organisation of cells aligned in four columns whereby column 1 is the medial-most column and column 4 the lateral-most. The six rows are named rows I to VI with row I the posterior most. ' $\mathrm{M}$ ' is the muscle cell that derives from the A-line neural lineages. Below the drawings is a DAPI-stained 6-row stage embryo with nuclei coloured according to the lineages shown in the figure. The larval drawing is adapted from ref. [110], Copyright Company of Biologists. The 112-cell and neural plate drawings are adapted from ref. [118], Copyright Elsevier. All other embryos were drawn with help from 3D-virtual embryo $[107,138]$.

Figure 3. Cells of the nervous system. Highly schematised drawings of the larva and its neurons. Anterior is to the left. (a) The central nervous system. I, II, III refer to the three types of photoreceptors with the position of their outer segments shown by red dots. Abbreviations as follows: Oc, Ocellus; Ls, lens cells; Ot, otolith, ac, antennal cells; cc, coronet cells; ec, eminens cell; L1, large ventroposterior interneuron; cp, contrapelo cells; cholinergic, the 5 pairs of ventro-lateral cholinergic trunk ganglion neurons (including confirmed motoneurons (mn)); on, ovoid neuron; ACIN, anterior caudal inhibitory neurons; pn, planate neurons. For the cholinergic and ACIN neurons, only one side is shown, but these neurons appear in pairs on both sides of the larvae (left and right). Below the CNS drawing are the cholinergic neurons found in the ventro-lateral trunk ganglion and their signature gene expression. A11.117 is characterised by cell body neurites as depicted [73]. During larval development the A11.118 moves around the A11.117 cell with a ventral trajectory and finishes posterior to the A11.117 cell [9]. (b) The peripheral nervous system. Abbreviations as follows: pn, palp neurons; RTEN, rostral trunk epidermal neurons; ATEN, apical trunk epidermal neurons (a, anterior; p, posterior); CEN, caudal epidermal neurons (d, dorsal; v, ventral); BTN, bipolar tail neuron. 
Figure 4. PNS lineages and the neural plate border cells. Anterior to the left. $M=$ muscle cells. The yellow dashed line delimits the CNS neural plate (including the A-line derived muscle cell, M, and the posterior b9.33 lineage of which its contribution to the CNS is not resolved). Lineages are identical on both sides of the bilaterally symmetrical embryo. (a) Lineages of the PNS neurons are indicated by labels and different colours. The colour code is: grey (medial) and pink (lateral) -a-line non-CNS anterior neural plate; light blue -lateral b6.5 derivatives; dark blue -posterior b-line. The aATEN lineage arises from the anterior lateral non-CNS neural plate in Ciona [86] as do both the aATENs and pATENs in Halocynthia (the pATEN lineage has not yet been delineated in Ciona) [89]. The RTEN lineages is described only in Halocynthia (Hr) [89]. Note the majority of PNS neurons arise from cells surrounding the CNS neural plate. In contrast, the vCEN lineage is found in the ventral epidermis on the other side of the embryo, far from the neural plate. Below the drawing is a cross section of a neural plate stage embryo showing the position of the ventral epidermal sensory neuron lineages compared to the neural plate. Cross section photo is from ref. [139], Copyright Company of Biologists. (b) The border cells described by Stolfi et al, 2015, outlined in red on one side of the embryo [82]. The border cells include the lateral a-line non-CNS neural plate (including the aATEN lineage), the lateral a-line CNS (including pigmented cells) and the entire b6.5-cell derivatives (dCEN, b-line CNS, b-line muscle). Colour code is as above, except the posterior neural border (in dark blue) includes the posterior-most b6.5 lineage. Embryo drawing adapted from ref. [130], Copyright Elsevier.

Figure 5. Patterning of the a-line neural lineages. (a) Anterior is up, all embryos shown in dorsal (developing neural plate) view. a-lineages of the CNS are shown in pink at the 64-celll stage and red from fate restriction at the 112-cell to neurula stages. At tailbud stages only the pigment cell precursors are shown. On the drawings, the pigment cell lineages are marked with a star. Below the drawings are schematics of a-line neural cells with ERK1/2 activation shown by black dots. Each division of these cells takes place along the anterior-posterior axis. Sister cell relationships are shown 
by bars on the left hand side of the embryo drawings. On the far right drawing of a tailbud stage embryo, the Wnt7-expressing dorsal neural tube is depicted by a green bar. The cell fate choices taking place are indicated below the schematics. Neural induction refers to the continuation of the neural induction process that began at the 32-cell stage. Adapted from ref. [118], Copyright Elsevier. (b) The role of Nodal during ocellus development. The photographs show a normal larva with the ocellus pigmented cell to the right side of the embryo and the photoreceptors (fluorescent colour) to the right of the ocellus pigmented cell. When Nodal signals are inhibited, the ocellus becomes symmetrical, the pigmented cell stays in the centre of the larva and the photoreceptors form on both the left and the right. The schematic describes the role of Nodal during ocellus patterning. The double-headed arrow represents Nodal-dependent movement of the ocellus pigment cell to the right hand side of the sensory vesicle. Rx, Opsin1 and Arrestin genes are all expressed in the photoreceptors. From ref. [127], Copyright Elsevier.

Figure 6. Patterning of the A-line neural lineages up to neural plate stage. (a) All embryos shown in vegetal pole view. The A-P axis corresponds to the developing CNS. At the 32- to 64-cell stage, Nodal induces lateral (column 3 and 4) over medial (column 1 and 2) neural fate and induces Deltalike expression in a lateral domain. At the 64- to 76- cell stage, Delta-like/Notch signals induce column 4 fate. By the early gastrula stage, Delta-like is now expressed in the lateral A-line neural precursors themselves and induces column 2 over column 1 fate. At the 6-row neural plate stage, differential activation of ERK1/2 along the anterior-posterior axis specifies row I over row II fates. Columns and rows are indicated on the schematics. $M$ indicates the muscle cell that derives from the A-line neural plate. (b) Summary of A-line neural plate patterning. Each cell receives a unique combination of signals, which specifies its distinct cell identity.

Figure 7. Cell lineages of the cholinergic trunk ganglion neurons and ACIN. Cell lineages of A9.16, A9.30 and A9.29 from the 6-row neural plate stage until the birth of the cholinergic trunk 
ganglion neurons. A9.16 lineages are coloured in yellow; A9.30 in tan and A9.29 in brown. (a) 6-row neural plate stage. (b) Neurula stage, note the A9.30 derivatives (A10.60, A10.59, tan) are now positioned posteriorally to the A9.16 derivatives (A10.32, A10.31, yellow). A10.57 is now postmitotic. (c) Drawing of an early tailbud stage embryo showing positions of these lineages in the lateral part of the posterior sensory vesicle (pSV), neck, trunk ganglion (tg) and tail nerve cord (tnc). A10.57 has moved into a ventro-lateral position of the neural tube. A11.117 and A11.118 are now postmitotic. Below the embryo drawing are the further lineages of the column 3 cells (tan and brown) up until the stage when the 5 pairs of post-mitotic cholinergic neurons are born. Only one side of the embryonic lineages are shown in lateral view. Non-cholinergic neurons have been rendered partially transparent to highlight the neurons. Note A12.239 has now shifted ventrally and A11.118 shifts ventrally and posteriorally around A11.117. While A10.57 is depicted in the 'tail nerve cord' domain, it will finally reside in the trunk ganglion just posterior to A11.118/A11.117. The early tailbud drawing was adapted from ref. [11], Copyright Company of Biologists. Cell lineages and positions in (a) and (b) are drawn from observations described in Nicol and Meinertzhagen, 1998 [12,13], and lineages and positions in (c) follow those described by Cole and Meinertzhagen, 2004 [9].

Figure 8. Patterning of the A-line lineages: the posterior sensory vesicle versus neck fate choice is governed by Fgf8. (a) The right hand side of the A-line neural plate and its combinatorial signalling code is indicated. The A9.16 (yellow) and A9.30 (tan) cells are coloured. (b) Only one side of the bilaterally symmetrical embryo is shown. Interactions between the descendants of A9.16 and A9.30 govern the gene regulatory network that specifies neck over posterior sensory vesicle fate. During later stages of development, the Pax2/5/8a+ domain subdivides into a Pax2/5/8a+/Hox+ and a Pax2/5/8a+/Hox - domain. Fgf8= Fgf8/17/18.

Figure 9. Patterning of the A-line lineages: column 3 neurons. (a) The right hand side of the A-line neural plate and its combinatorial signalling code is indicated. The A9.30 and A9.29 sister cells are 
coloured in tan. (b) Only one side of the bilaterally symmetrical embryo is shown. Cellular interactions and part of the known gene regulatory network during the step-by-step specification of the 5 pairs of cholinergic neurons of the trunk ganglion are shown. The ACINs derive from A11.116 lineage. Cells that leave the cholinergic lineage are not coloured. Circled cells indicate the post-mitotic cholinergic neurons. White squares represent cell lineages that remain mitotic at least until the $13^{\text {th }}$ cell division [9].

\section{Further Reading/Resources}

http://www.aniseed.cnrs.fr/ANISEED For genome browser, virtual embryo, searchable gene expression pattern.

http://ghost.zool.kyoto-u.ac.jp/SearchGenomekh.html Expressed sequence tag database and genome browser.

http://ghost.zool.kyoto-u.ac.jp/otherfr_kh.html Gene expression pattern database for transcription factors, signalling molecules and zinc finger proteins. 
XENOPUS

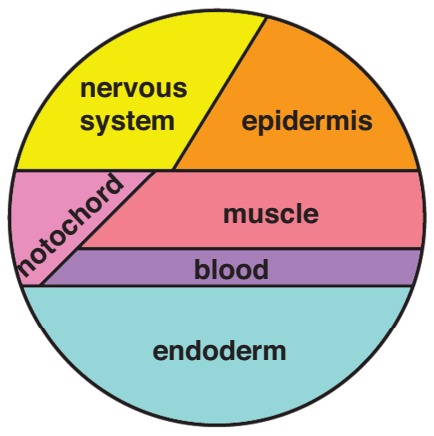

ASCIDIAN

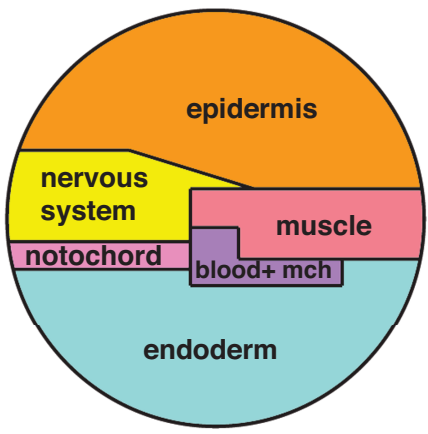


(a)

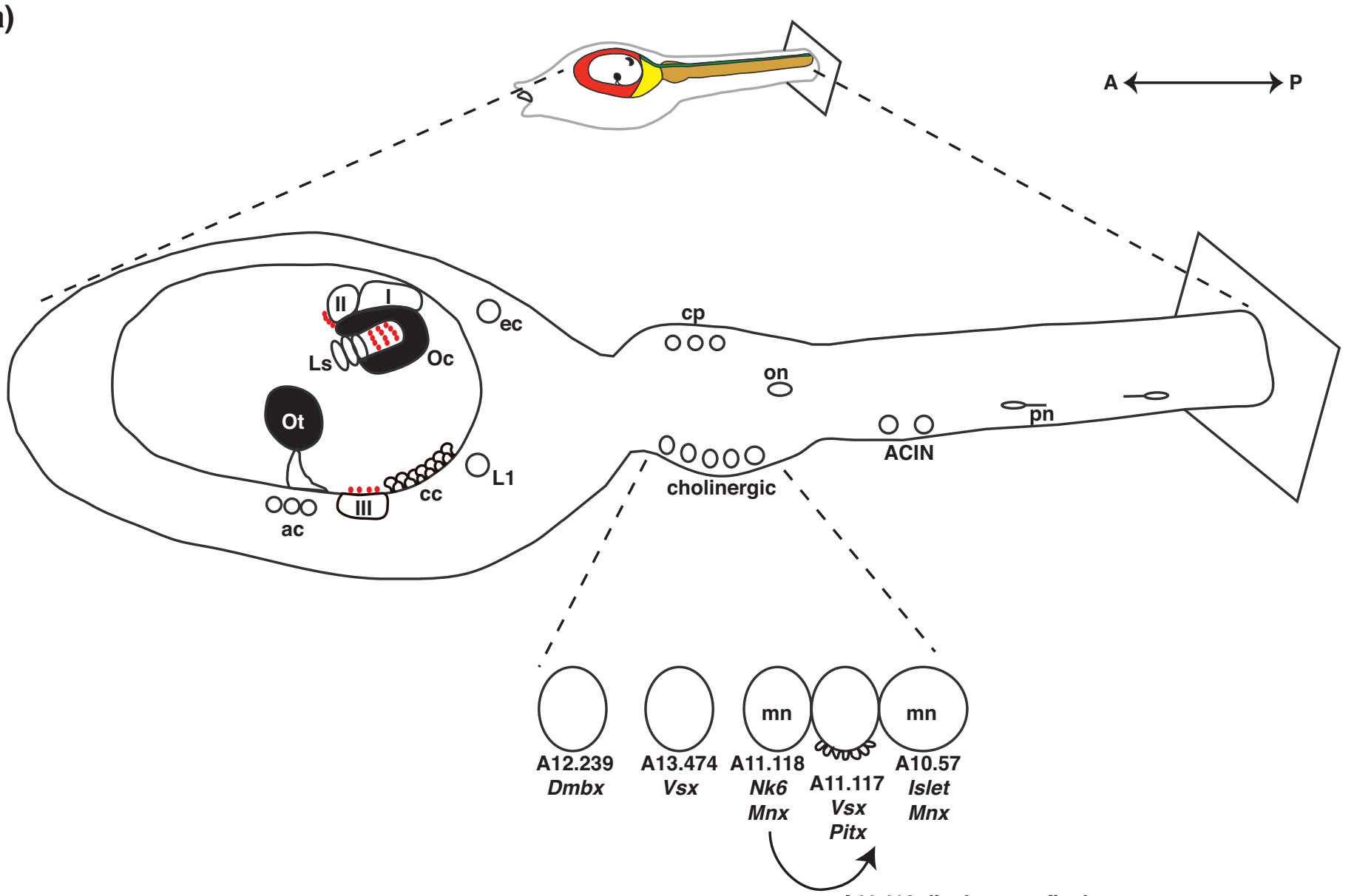

A11.118 displaces to final

position posterior to A11.117

(b)

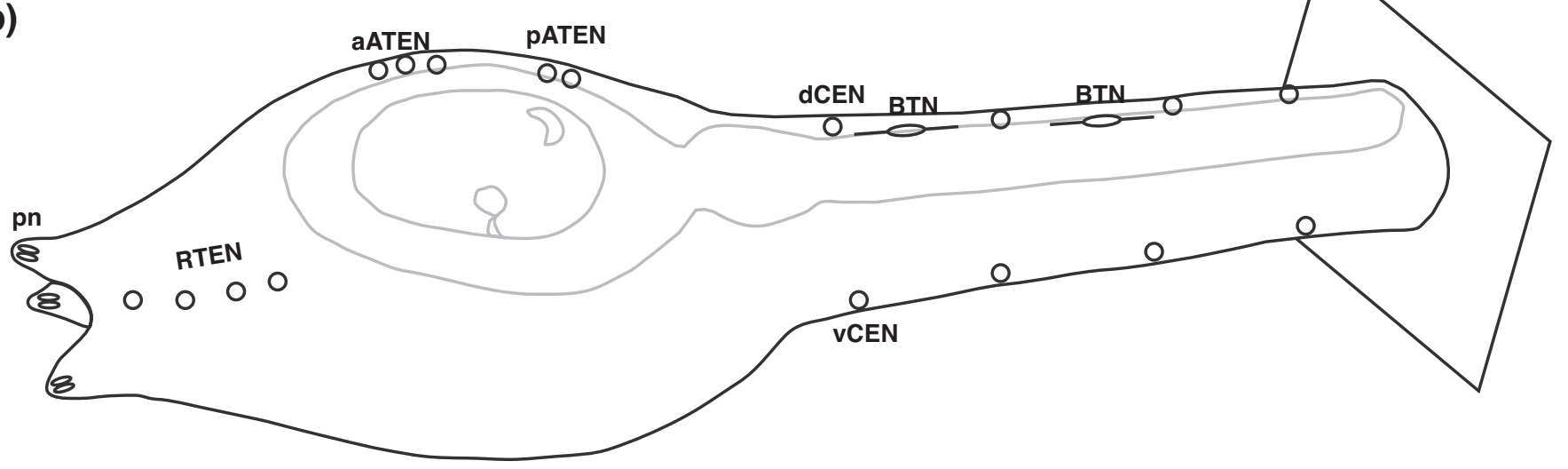

Figure 3 
(a) PNS lineages dorsal view

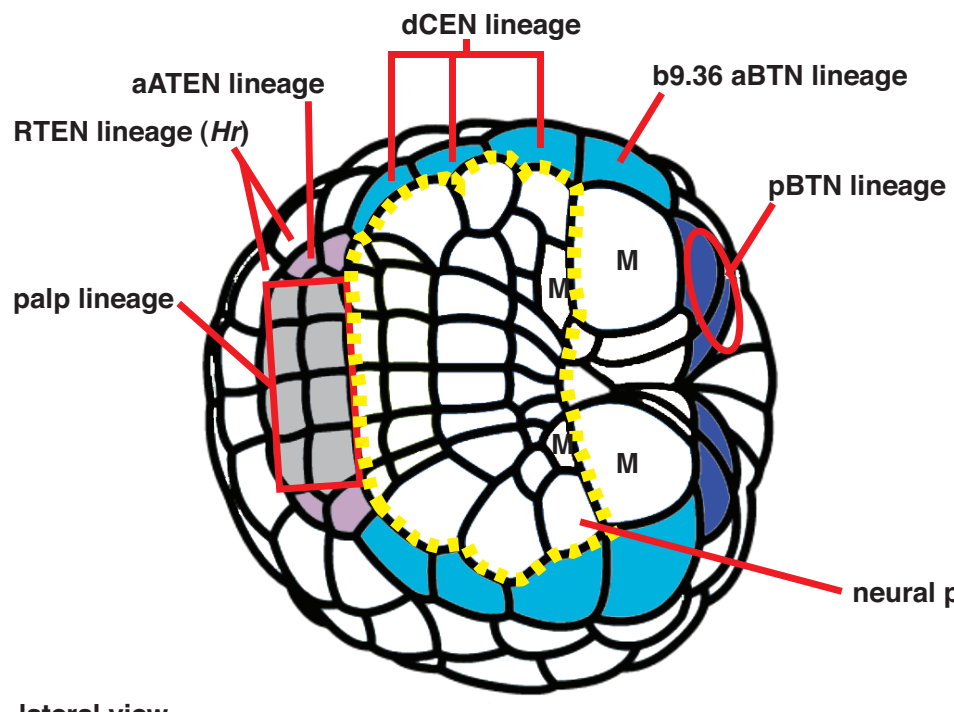

lateral view

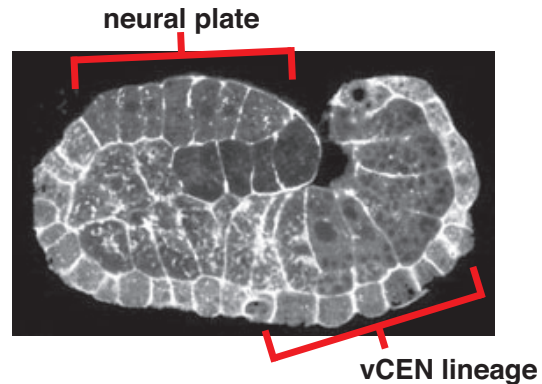

VEN Iineage (b) neural border
dorsal view

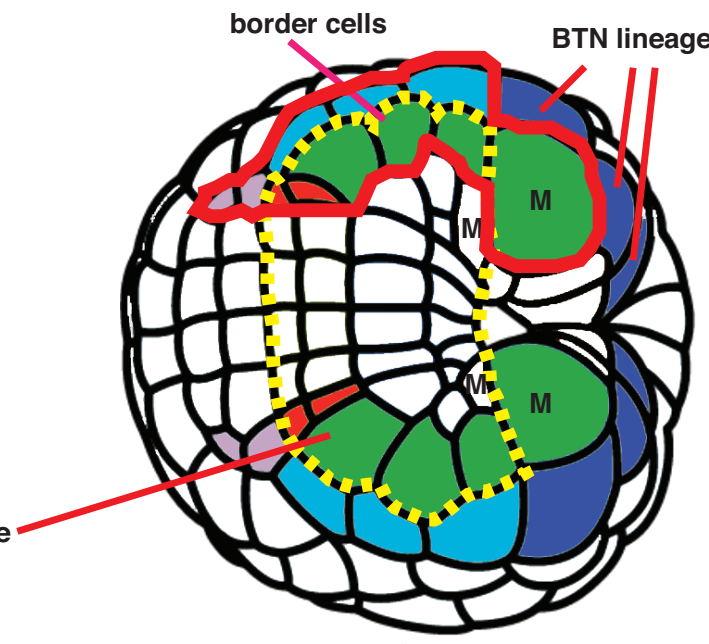

Figure 4 
(a)

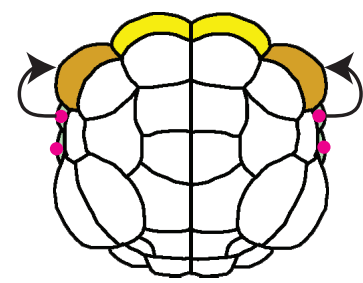

Nodal • lateral 'v' medial
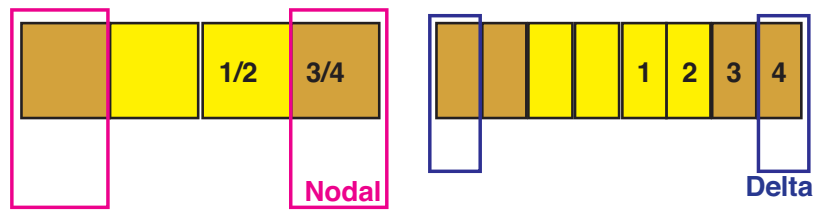

early gastrula stage

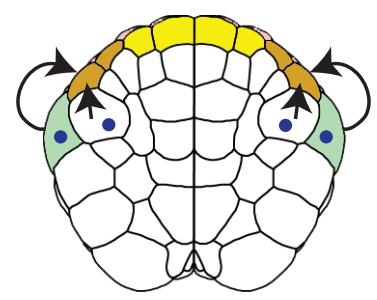

Delta-like• column 4

Delta-like • column 2 'v' column 1

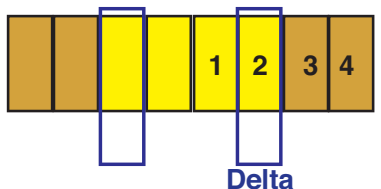

6-row neural plate stage

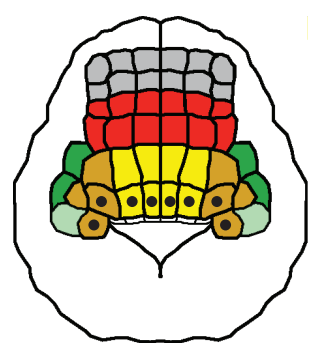

Differential ERK1/2 activation • row I 'v' row II

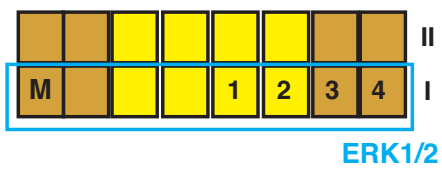

(b)

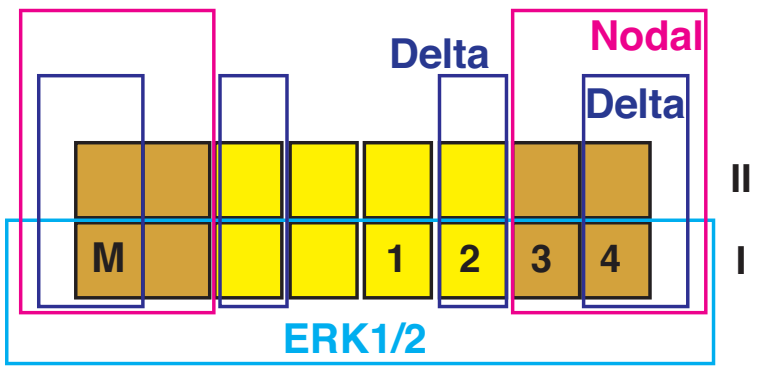

Figure 6 
(a)

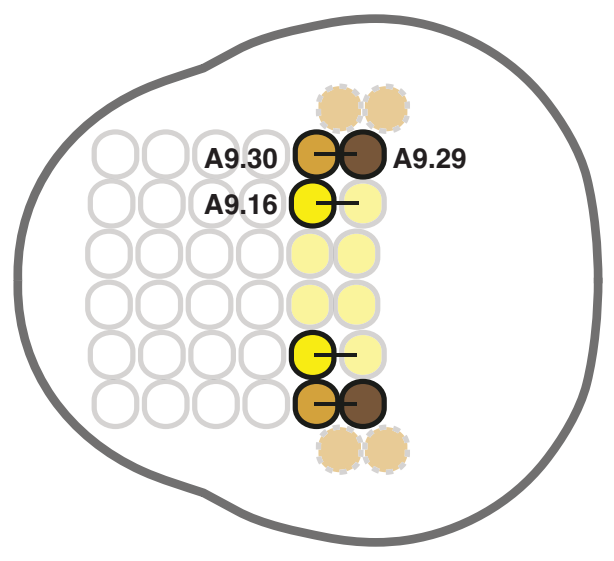

(b)

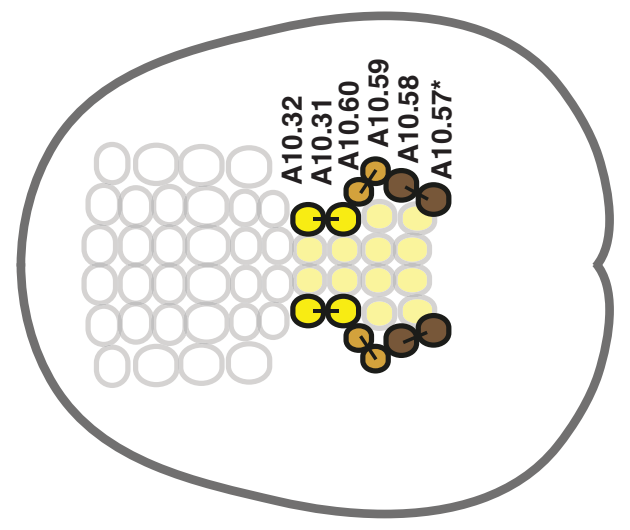

(c)

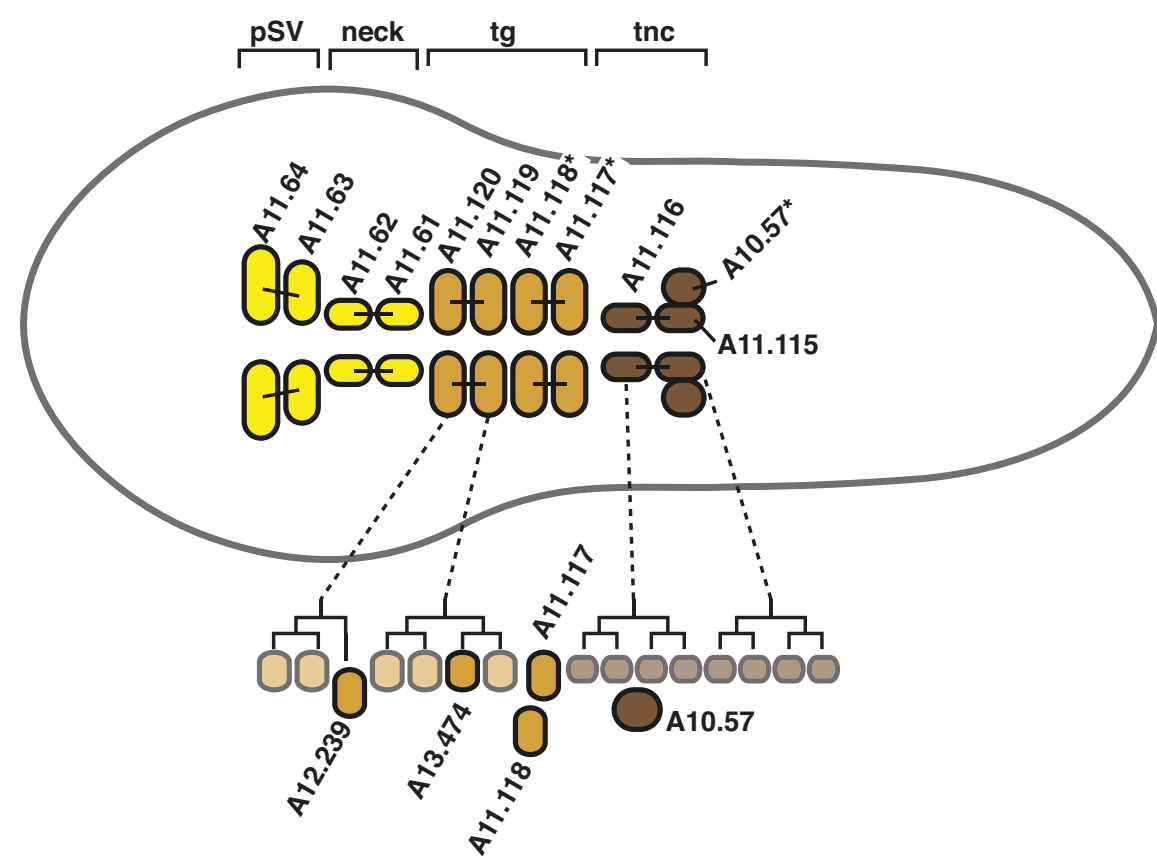

Figure 7 
(a)

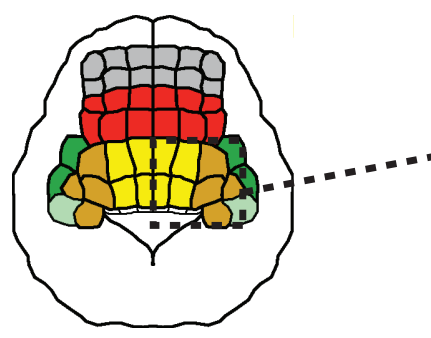

Nodal

(b)

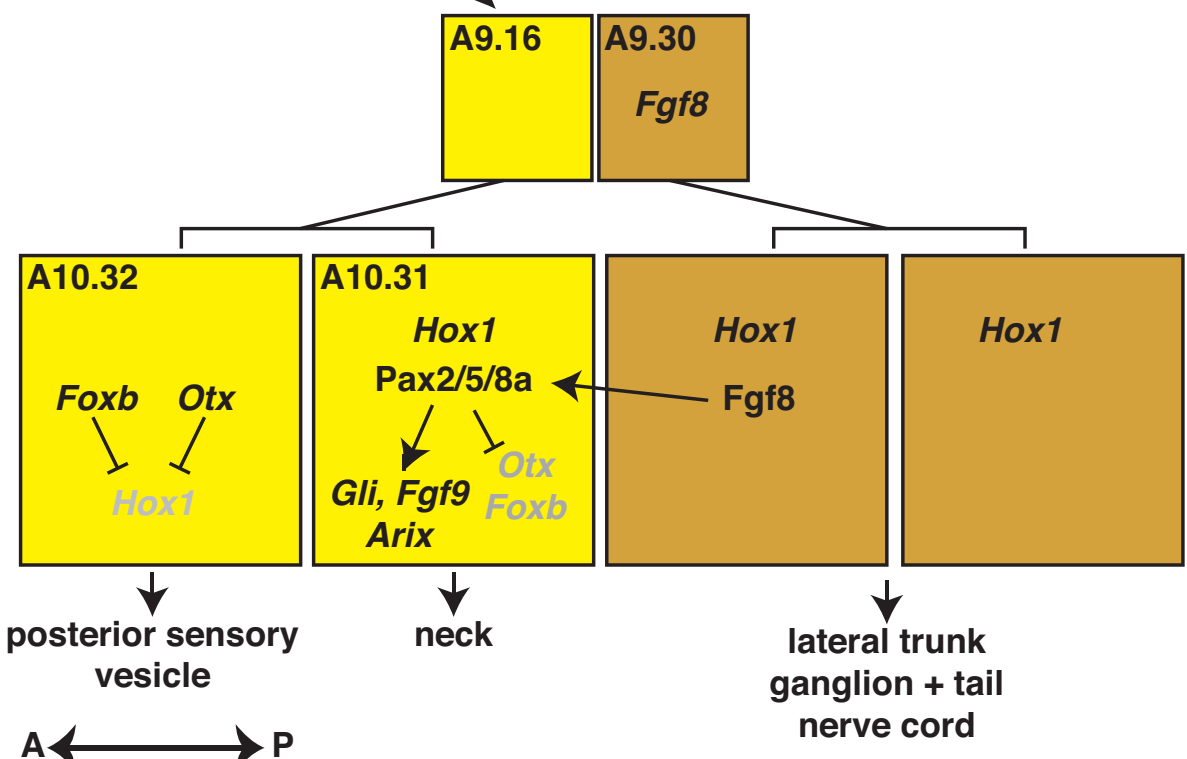

Figure 8 
